Article

\title{
Experimental and Theoretical Studies of $\alpha$-Linolenic Acid as Green Corrosion Inhibitor for Carbon Steel in 0.5 M Sulfuric Acid
}

\author{
I.A. Hermoso-Diaz ${ }^{1}$, R. Lopez-Cecenes ${ }^{2} \mathbb{D}$, J.P. Flores-De los Rios ${ }^{3}$, L.L. Landeros-Martínez ${ }^{4}$, \\ E. Sarmiento-Bustos ${ }^{5}$, J. Uruchurtu-Chavarin ${ }^{6}$ and J.G. Gonzalez-Rodriguez ${ }^{6, * \mathbb{D}}$
}

check for updates

Citation: Hermoso-Diaz, I.;

Lopez-Cecenes, R.; Rios, J.F.-D.1.;

Landeros-Martínez, L.;

Sarmiento-Bustos, E.;

Uruchurtu-Chavarin, J.;

Gonzalez-Rodriguez, J. Experimental

and Theoretical Studies of

$\alpha$-Linolenic Acid as Green Corrosion Inhibitor for Carbon Steel in 0.5 M

Sulfuric Acid. Molecules 2021, 26, 6169.

https://doi.org/10.3390/

molecules 26206169

Academic Editor: Bogumil E. Brycki

Received: 21 September 2021

Accepted: 7 October 2021

Published: 13 October 2021

Publisher's Note: MDPI stays neutral with regard to jurisdictional claims in published maps and institutional affiliations.

Copyright: (c) 2021 by the authors. Licensee MDPI, Basel, Switzerland. This article is an open access article distributed under the terms and conditions of the Creative Commons Attribution (CC BY) license (https:/ / creativecommons.org/licenses/by/ $4.0 /)$.
1 Department of Chemical Engineering and Applied Chemistry, University of Toronto, Toronto, ON M5S 3E5, Canada; alondra.hermosodiaz@utoronto.ca

2 Chemical Science and Engineering Faculty, Morelos State Autonomous University, Cuernavaca 62209, Mexico rlopez@uaem.mx

3 Chemical Science Faculty, Chihuahua Autonomus University, Chihuahua 31125, Mexico; jpdelosrios@uach.mx

4 Engineering Faculty, Chihuahua Autonomus University, Chihuahua 31125, Mexico; lilanderos@uach.mx

5 Industrial Mechanical Division, Morelos State Emiliano Zapata Technological University, Emiliano Zapata 62565, Mexico; estelasarmiento@utez.edu.mx

6 Research Centre in Engineering and Applied Sciences, Morelos State Autonomous University, Cuernavaca 62209, Mexico; juch25@uaem.mx

* Correspondence: ggonzalez@uaem.mx

\begin{abstract}
A component of Salvia hispanica, $\alpha$-linolenic acid, has been evaluated as a green corrosion inhibitor for 1018 carbon steel in $0.5 \mathrm{M}$ sulfuric acid using weight loss tests, potentiodynamic polarization curves and electrochemical impedance spectroscopy (EIS) measurements. Theoretical calculations using Density Functional Theory (DFT) were used also. The results have shown that this compound is a good corrosion inhibitor, with an efficiency which increased with an increase in its concentration up to $600 \mathrm{ppm}$, but it decreased with a further increase in the concentration. $\alpha$-linolenic acid formed protective corrosion products layer because it was chemically adsorbed onto the steel surface according to a Langmuir type of adsorption isotherms. Polarization curves have shown that $\alpha$-linolenic acid is a good, mixed type of inhibitor with a predominant effect on the cathodic hydrogen evolution reactions. EIS measurements indicated a charge transfer-controlled corrosion process. DFT calculations indicated that $\alpha$-linolenic acid was more efficient in an acidic environment than in a neutral one because has a high tendency to donate electrons and can be easily protonated. In addition to this, it had the highest $\mathrm{E}_{\mathrm{HUMO}}$ value, the best chemical reactivity, the greatest tendency to transfer electrons and a greater facility of modifying its electronic configuration in the presence of carbon steel specimens according to its chemical hardness value.
\end{abstract}

Keywords: carbon steel; green inhibitor; acid corrosion; quantum chemistry

\section{Introduction}

The study of corrosion of metals and alloys is a very important fact from both academic and industrial points of view due to big economical losses and many accidents it causes to a country [1,2]. There exist many processes in the industry where involved metals are in contact with aggressive solutions such as sulfuric $\left(\mathrm{H}_{2} \mathrm{SO}_{4}\right)$, hydrochloric $(\mathrm{HCl})$ and phosphoric acid $\left(\mathrm{H}_{3} \mathrm{PO}_{4}\right)$, which produce degradation on them [2]. One of the most widely used forms to fight metals corrosion is the use of corrosion inhibitors [3]. For the particular case of iron and steel, there exist a high number of synthetic inhibitors [4-6]; however, they have the main drawback that they are toxic, harmful for the environment and humans and are very expensive. Thus, there is an increasing need to use more environmentally friendly corrosion inhibitors, such as those obtained from plant seeds, leaves, roots, etc., 
which are called "naturally occurring corrosion inhibitors" [7-25]. In the last decade, an extensive number of research works related to these kinds of substances have been published. For instance, Pimenta dioica was evaluated by Anupama et al. [26] as a green corrosion inhibitor for mild steel in $\mathrm{HCl}$. For this, polarization curves, electrochemical impedance spectroscopy and theoretical computational calculations for the molecular components were used. In another work [27], modified lignin was evaluated as a green corrosion inhibitor for mild steel in $\mathrm{HCl}$ by using the same electrochemical and gravimetric techniques. The synergistic effect of several naturally occurring inhibitors, including polyaspartic acid, polyepoxysuccinic acid, polyamino polyether methylene phosphonate, sodium gluconate and $\mathrm{Zn}^{2+}$, were evaluated by Zhang et al. [28] for carbon steel in soft water. In a different study, Banana peels were evaluated as green corrosion inhibitors for mild steel in $\mathrm{HCl}$. The authors found big differences between raw and ripe banana peel extracts [29]. Similarly, Brassica oleracea extract was evaluated as a naturally occurring inhibitor for X-52 pipeline steel in $0.5 \mathrm{M} \mathrm{H}_{2} \mathrm{SO}_{4}$ [30], finding an increase in the inhibitor efficiency with the inhibitor concentration and temperature up to certain values. A further increase in both the inhibitor concentration and testing temperature produced a decrease in the inhibitor efficiency. In a similar way, Retama monosperma [31], Eleusine aegyptiaca and Croton rottleri leaf extracts [32] have been evaluated as green corrosion inhibitors for mild steel in $\mathrm{HCl}$.

In Mexico, since many centuries ago, Salvia hispanica L. has been a widely used seed for food and medicine $[33,34]$ due to the fact that its fatty acids are highly unsaturated, containing mainly linoleic and $\alpha$-linolenic acids, two polyunsaturated fatty acids, which cannot be produced in the human body, in addition to myrcetin, quercetin, kaempferol and caffeic acid, which act as potent antioxidants. Decreasing the level of cholesterol and triglyceride is one of the most important beneficial effects, as well as reducing blood pressure and the risk of heart disease. Additionally, some anti-inflammatory properties have been attributed to their omega-3-containing acids in Salvia hispanica, which make them beneficial for patients with rheumatoid arthritis and lupus $[35,36]$. Salvia hispanica extract has been previously evaluated as a green corrosion inhibitor for 1018 carbon steel in $0.5 \mathrm{M} \mathrm{H}_{2} \mathrm{SO}_{4}$ [37]. It was reported that Salvia hispanica inhibited both uniform and localized types of corrosion, with an efficiency that increased with increasing its concentration but decreased with increasing the testing temperature. The pitting potential increased and the passive current density decreased with increasing the inhibitor concentration. Thus, the goal of this paper is to evaluate the use of $\alpha$-linolenic acid, one of the main components of Salvia hispanica, as a corrosion inhibitor for 1018 carbon steel in $0.5 \mathrm{M} \mathrm{H}_{2} \mathrm{SO}_{4}$ to know whether $\alpha$-linolenic acid is mainly responsible for the corrosion inhibitive ability that Salvia hispanica possesses. In addition to this, to find a correlation between the corrosion inhibition properties and the inhibitor structure, the Density Functional Theory (DFT), a widely used technique [8-10,38-41], was used.

\section{Experimental Procedure}

\subsection{Testing Material}

Testing material includes 1018 carbon steel rods $6 \mathrm{~mm}$ in diameter containing $0.14 \% \mathrm{C}$, $0.90 \% \mathrm{Mn}, 0.30 \% \mathrm{~S}, 0.030 \% \mathrm{P}$ and balanced Fe. For weight loss tests, they were abraded up to 600-grade emery paper, washed and dried with hot air.

\subsection{Testing Solution}

The testing solution included $0.5 \mathrm{M} \mathrm{H}_{2} \mathrm{SO}_{4}$ prepared with analytical grade reagents and distilled water. $\alpha$-linolenic acid was purchased from Sigma-Aldrich (Mexico City, Mexico) with a molecular structure, as shown in Figure 1. The concentrations used include $100,200,400,600,800$ and $1000 \mathrm{ppm}$. 


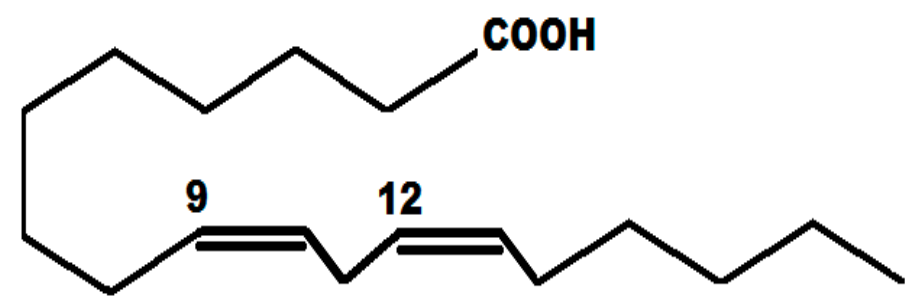

Figure 1. Chemical structure of $\alpha$-linolenic acid.

\subsection{Weight Loss Measurements}

For each inhibitor concentration, three specimens were used, and tests lasted $72 \mathrm{~h}$ at room temperature $\left(25^{\circ} \mathrm{C}\right), 40$ and $60^{\circ} \mathrm{C}$. Specimens weight was taken before and after tests. Weight loss, $\Delta \mathrm{m}$, was calculated as follows:

$$
\Delta \mathrm{m}=\left(\mathrm{m}_{2}-\mathrm{m}_{1}\right) / \mathrm{A}
$$

where $m_{2}$ and $m_{1}$ are the specimen's weight before and after the tests, respectively, and A is the specimen area. On the other hand, inhibitor efficiency, I.E., was calculated as follows:

$$
\text { I.E. }(\%)=\left(\Delta \mathrm{m}_{2}-\Delta \mathrm{m}_{1}\right) / \Delta \mathrm{m}_{2} \times 100
$$

where $\Delta \mathrm{m}_{2}$ and $\Delta \mathrm{m}_{1}$ are the weight loss in the absence and presence of the inhibitor, respectively.

\subsection{Electrochemical Techniques}

\subsubsection{Potentiodynamic Polarization Curves}

For electrochemical tests, coupons of carbon steel were encapsulated in a commercial resin, leaving an exposed area of $0.28 \mathrm{~cm}^{2}$. Employed electrochemical techniques include potentiodynamic polarization curves and electrochemical impedance spectroscopy (EIS). A standard three-electrode glass cell was used for these experiments, with a saturated calomel electrode (SCE) as the reference electrode and a graphite rode as the auxiliary electrode. Before starting the experiments, the free corrosion potential value, $\mathrm{E}_{\mathrm{corr}}$, was measured until it reached a stable value, normally $30 \mathrm{~min}$. For potentiodynamic polarization curves, steel was polarized from -1000 up to $+2500 \mathrm{mV}$ with respect to the $\mathrm{E}_{\mathrm{corr}}$ value, at a scan rate of $1 \mathrm{mV} / \mathrm{s}$. Inhibitor efficiency percent values, I.E., were obtained according to the next equation:

$$
\text { I.E. }(\%)=100\left(\text { Icorr }_{1}-\text { Icorr }_{2}\right) / \text { Icorr }_{2}
$$

where $\mathrm{I}_{\text {corr2 }}$ and $\mathrm{I}_{\text {corr1 }}$ are the corrosion current density values in the presence and absence of the inhibitor, respectively, which were calculated by using the Tafel extrapolation method.

\subsubsection{Electrochemical Impedance Spectroscopy Studies}

EIS measurements were carried out in a PC4 300 Gamry potentiostat (Queretaro, Mexico) by applying a signal of $\pm 10 \mathrm{mV}$ around the $\mathrm{E}_{\text {corr }}$ value at the interval frequency between $10 \mathrm{KHz}$ and $0.5 \mathrm{~Hz}$, obtaining 50 points per decade. Inhibitor efficiency values were calculated using

$$
\text { I.E. }(100 \%)=100\left(R_{\mathrm{ct} 2}-R_{\mathrm{ct} 1}\right) / \mathrm{R}_{\mathrm{ct} 2}
$$

where $R_{\mathrm{ct} 2}$ and $\mathrm{R}_{\mathrm{ct} 1}$ are the charge transfer resistance values with and without the addition of the inhibitor, respectively.

\subsection{Computational Studies}

In order to try to find a correlation between the inhibitory properties and the electronic properties of the $\alpha$-linolenic acid, some quantum chemical calculations were performed. Quantum chemical calculation is the most appropriate method to investigate adsorption and inhibition mechanism. In order to construct a composite index of an inhibitor molecule, 
it may be important to focus on parameters that directly influence the electronic interaction of the inhibitor molecules with the metal surface. For this, the Density Functional Theory (DFT) with B3LYP Beck's three-parameter exchange functional along with Yang and Parr non-local correlation functional (B3LYP) and $6-311 \mathrm{G}^{+}$basis $[42,43]$ was used. The energies of the highest occupied molecular orbital $\left(\mathrm{E}_{\mathrm{HOMO}}\right)$ and lowest unoccupied molecular orbital ( $\left.\mathrm{E}_{\mathrm{LUMO}}\right)$, as well as the dipolar moment, $\mu$, are very important quantum chemical parameters. A computational study was performed in the presence of water as the solvent, using the IEFCPCM (integral equation formalism PCM) method coupled to UAKS radii in the PCM (polarizable Continuum Model) [44,45].

Within the framework of the Density Functional Theory, the chemical potential is defined as the negative of the electronegativity.

$$
X=-(\partial E / \partial N)
$$

Whereas the hardness $(\eta)$ is defined as:

$$
\eta=1 / 2\left(\partial^{2} \mathrm{E} / \partial \mathrm{N}^{2}\right)
$$

where $\mathrm{E}$ is the electronic energy and $\mathrm{N}$ is the number of electrons.

$\mathrm{I}$ and $\mathrm{A}$ are related in turn to $\mathrm{HOMO}$ and LUMO, using equations:

$$
\begin{aligned}
& \mathrm{I}=-\mathrm{HOMO} \\
& \mathrm{A}=-\mathrm{LUMO}
\end{aligned}
$$

These quantities are related to the electron affinity (A) and ionization potential (I) using the following equations:

$$
\begin{gathered}
X=(I+A) / 2, X=-(\mathrm{LUMO}+\mathrm{HOMO}) / 2 \\
\eta=(\mathrm{I}-\mathrm{A}) / 2, X=-(\mathrm{LUMO}-\mathrm{HOMO}) / 2
\end{gathered}
$$

The global electrophilicity index $(\omega)$ is:

$$
\omega=\mu^{2} / 2 \eta
$$

The Fukui function (FF), which measures reactivity in a local sense, using a scheme of finite difference approximations. This procedure condenses the values around each atomic site into a single value that characterizes the atom in the molecule. With this approximation, the condensed Fukui becomes:

$$
\begin{aligned}
& f^{+}{ }_{k}=q_{k}(N+1)-q_{k}(N) \text { (for nucleophilic attack) } \\
& f^{-}{ }_{k}=q_{k}(N)-q_{k}(N-1) \text { (for electrophilic attack) }
\end{aligned}
$$

where $\mathrm{q}_{\mathrm{k}}(\mathrm{N}+1), \mathrm{q}_{\mathrm{k}}(\mathrm{N})$ and $\mathrm{q}_{\mathrm{k}}(\mathrm{N}-1)$ are charge values of atom $\mathrm{k}$ for cation, neutral and anion, respectively [46].

Similar to FF for a nucleophilic and electrophilic attack, the local softness and local philicity were used to provide more information on the reactivity of atoms in the $\alpha$-linolenic acid molecule.

The local softness [47] and local philicity [48] are given by

$$
\begin{aligned}
& S_{\mathrm{k}}^{\alpha}=S f_{\mathrm{k}}{ }^{\alpha} \\
& \omega_{\mathrm{k}}{ }^{\alpha}=\omega f_{\mathrm{k}}{ }^{\alpha}
\end{aligned}
$$

where $\alpha=+,-$ represent nucleophilic and electrophilic attacks respectively.

On the other hand, the dual local descriptors, such as dual Fukui $\Delta f_{\mathrm{k}}$, is defined as the difference between the nucleophilic and electrophilic Fukui functions [49]. The dual 
local softness $\Delta S_{\mathrm{k}}$ (difference between the nucleophilic and electrophilic local softness) and the philicity $\Delta \omega_{\mathrm{k}}$ (difference between the nucleophilic and electrophilic local philicity) are more accurate and consistent tools than the aforementioned local reactivity indices [50]. $\Delta f_{\mathrm{k}}, \Delta S_{\mathrm{k}}$ and $\Delta \omega_{\mathrm{K}}$ are given by

$$
\begin{gathered}
\Delta f_{\mathrm{k}}=f_{\mathrm{k}}^{+}-f_{\mathrm{k}}^{-} \\
\Delta S_{\mathrm{k}}=S_{\mathrm{k}}^{+}-S_{\mathrm{k}}^{-} \\
\Delta \omega_{\mathrm{k}}={\omega_{\mathrm{k}}}^{+}-{\omega_{\mathrm{k}}}^{-}
\end{gathered}
$$

\section{Results and Discussion}

\subsection{Weight Loss}

The change in the weight loss and inhibitor efficiency with the inhibitor concentration at the different testing temperatures is given in Figure 2. This figure shows that the weight loss decreases with an increase in the inhibitor concentration, but it increases with an increase in the temperature. Additionally, inhibitor efficiency increases with an increase in the inhibitor concentration, but it decreases when the testing temperature increases. Similar results were obtained by Hermoso-Diaz et al. [37], who worked with Salvia hispanica extract but obtained a highest inhibitor efficiency value of $91 \%$ with the addition of $1000 \mathrm{ppm}$, whereas, in this research work, the highest inhibitor efficiency was $85 \%$, but with less of the inhibitor, it became $600 \mathrm{ppm}$. This decrease in the metal weight loss is due to the adsorption of $\alpha$-linolenic acid onto the steel surface with the formation of a layer of protective corrosion products, and, in order to elucidate on the way that the inhibitor is adsorbed, different adsorption isotherms, including Langmuir, Temkin and Frumkin. As can be seen from Figure 3, the best fitting was obtained with the Langmuir type of adsorption isotherm [51], which is given by:

$$
\frac{\mathrm{C}_{\mathrm{inh}}}{\theta}=\frac{1}{\mathrm{~K}_{\mathrm{ads}}}+\mathrm{C}_{\mathrm{inh}}
$$

where the inhibitor concentration is represented by $\mathrm{C}_{\mathrm{inh}}, \mathrm{K}_{\mathrm{ads}}$ is the adsorption constant $=3.12 \times 10^{-2} \mathrm{~L} / \mathrm{mg}$, and $\theta$ represents the surface coverage, obtained by dividing the inhibitor efficiency by 100 .
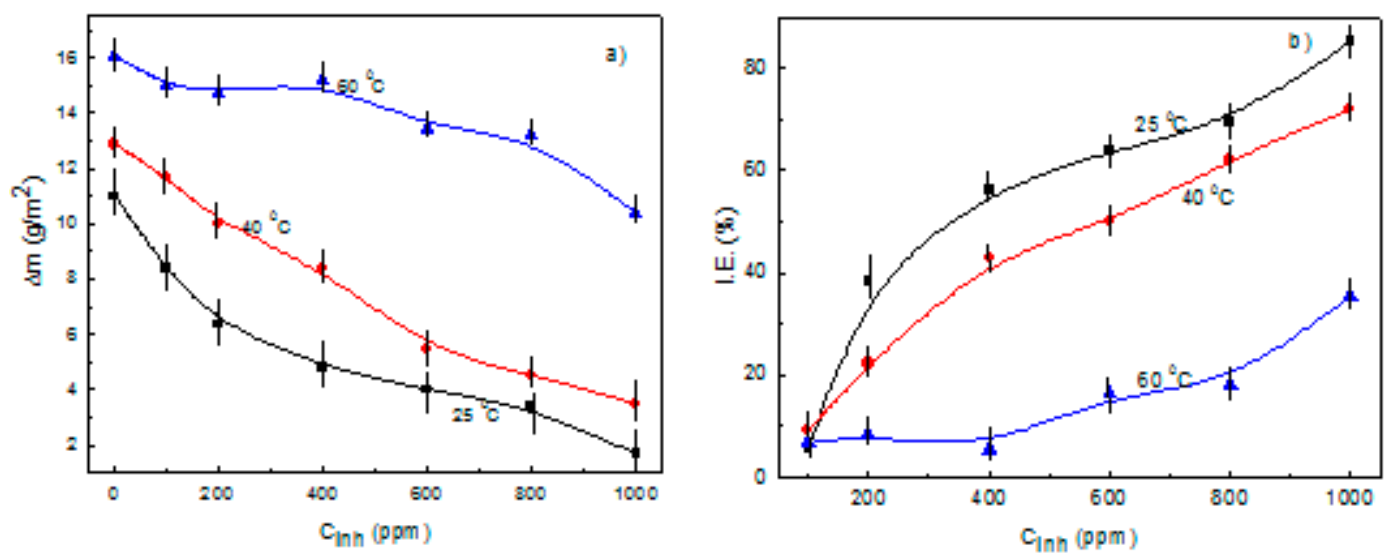

Figure 2. Effect of $\alpha$-linolenic acid concentration on the (a) weight loss and (b) inhibitor efficiency for carbon steel in $0.5 \mathrm{M}$ $\mathrm{H}_{2} \mathrm{SO}_{4}$ at different temperatures. 


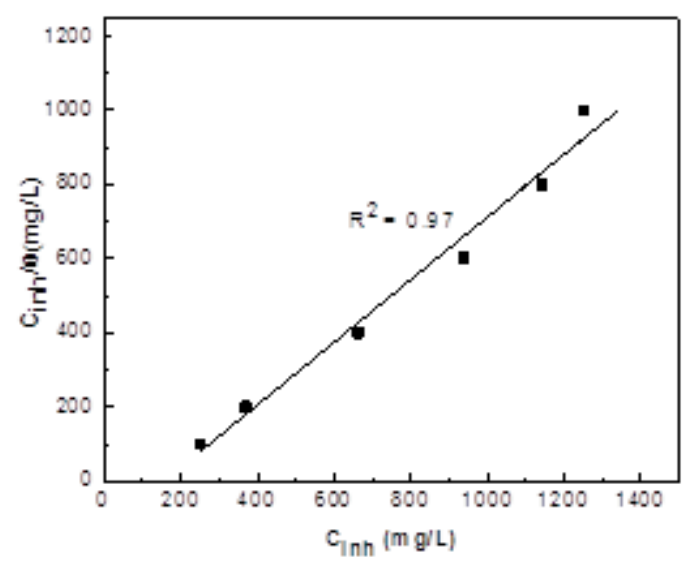

Figure 3. Langmuir adsorption isotherm for carbon steel in $0.5 \mathrm{M} \mathrm{H}_{2} \mathrm{SO}_{4}$ in the presence of $\alpha$-linolenic acid.

There exists a relationship between the adsorption constant, $\mathrm{K}_{\mathrm{ads}}$, and the standard adsorption free energy, $\Delta G_{\text {ads }}^{0}$, which is:

$$
\Delta \mathrm{G}_{\mathrm{ads}}^{0}=-\mathrm{RT} \operatorname{In}\left(10^{6} \mathrm{~K}_{\mathrm{ads}}\right)
$$

where $\mathrm{R}$ is the universal gas constant, and $\mathrm{T}$ is the absolute temperature. From the intercepts of the straight lines $C_{i n h} / \theta-Y$ axis, and by knowing that the concentration of water in the solution is $106 \mathrm{mg} / \mathrm{L}$, the value obtained for $\Delta \mathrm{G}_{\mathrm{ads}}^{0}$ is $-43.34 \mathrm{~kJ} \mathrm{~mol}^{-1}$. Generally, for values of $\Delta \mathrm{G}_{\text {ads }}^{0}$ around $-20 \mathrm{~kJ} \mathrm{~mol}^{-1}$ or less negative, the type of adsorption is regarded as physisorption; those around $-40 \mathrm{~kJ} \mathrm{~mol}^{-1}$ or more negative are associated with chemisorption [51]; therefore, a value of $-43.34 \mathrm{~kJ} \mathrm{~mol}^{-1}$ indicates a chemical adsorption [51]. The negative value for $\Delta \mathrm{G}_{\text {ads }}^{0}$ indicates that the adsorption process is spontaneous.

Activation energy, $\mathrm{E}_{\mathrm{a}}$, for carbon steel in the absence and presence of $\alpha$-linolenic acid was calculated using the Arrhenius type of equation:

$$
\log (\Delta \mathrm{m})=-\mathrm{E}_{\mathrm{a}} / 2.3 \mathrm{RT}+\mathrm{A}
$$

where $\mathrm{A}$ is the Arrhenius pre-exponential factor. By plotting the weight loss results at the different inhibitor concentrations as a function of $-1 / 2.3 \mathrm{RT}$, as shown in Figure 4, the different values of activation energy can be obtained, and these results are given in Table 1. Table 1 shows that the activation energy values are larger in the presence of the inhibitor, which designates that the adsorption of inhibitor is mainly the physical (electrostatic) adsorption up to a concentration of $100 \mathrm{ppm}$, while the chemical bonding would arise between the inhibitor molecules and the steel surface at inhibitor concentrations higher than 100 ppm [52,53].

\subsection{Polarization Curves}

The effect of $\alpha$-linolenic acid concentration in the polarization curves for 1018 carbon steel in $0.5 \mathrm{M} \mathrm{H}_{2} \mathrm{SO}_{4}$ is shown in Figure 5. It can be seen that in all cases, curves display an active-passive behavior, where the $\mathrm{E}_{\text {corr }}$ value practically was unaffected by the addition of $\alpha$-linolenic acid, as can be seen in Table 2. The free corrosion potential for the uninhibited solution was $-430 \mathrm{mV}$, and it remained around this value with the addition of the different inhibitor concentrations up to 400 ppm, but when 600 ppm or higher inhibitor concentrations were added, the $\mathrm{E}_{\mathrm{corr}}$ reached more active values than those obtained in the absence of inhibitor, between -455 and $-472 \mathrm{mV}$. The corrosion current density value, $\mathrm{I}_{\text {corr }}$, decreased, and the polarization resistance value increased with the addition of the inhibitor up to $600 \mathrm{ppm}$, but they followed the opposite behavior with a further increase in the inhibitor concentration. The decrease in the $\mathrm{I}_{\text {corr }}$ value with an increase in the inhibitor concentration is due to the adsorption of the $\alpha$-linolenic acid on the steel surface [29-32]. 


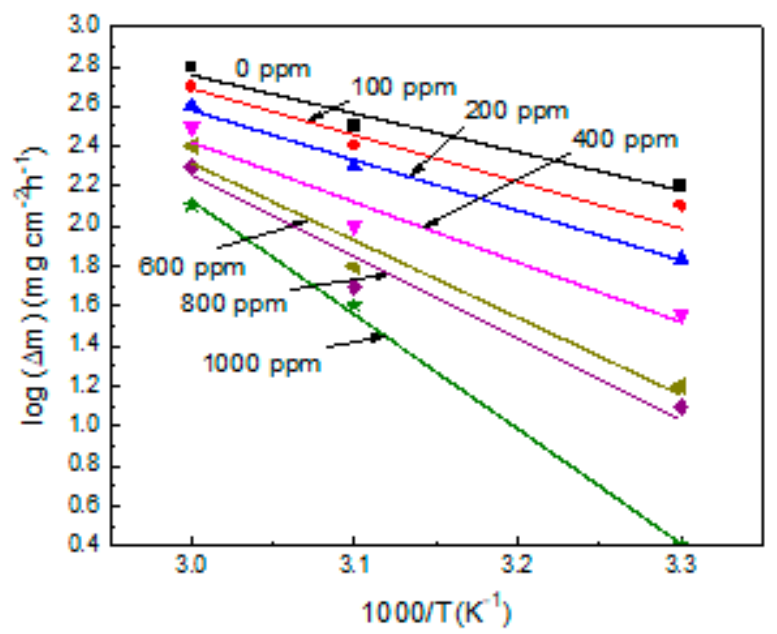

Figure 4. Arrhenius $\mathrm{E}_{\mathrm{a}}$ activation energy plots for carbon steel in $0.5 \mathrm{M} \mathrm{H}_{2} \mathrm{SO}_{4}$ containing different concentrations of $\alpha$-linolenic acid.

Table 1. Effect of $\alpha$-linolenic acid concentration on the activation energy for 1018 carbon steel in $0.5 \mathrm{M} \mathrm{H}_{2} \mathrm{SO}_{4}$.

\begin{tabular}{|c|c|}
\hline $\begin{array}{c}\mathrm{C}_{\mathrm{inh}} \\
(\mathrm{ppm})\end{array}$ & $\begin{array}{c}E_{a} \\
\left(\mathrm{~kJ} \mathrm{~mol}^{-1}\right)\end{array}$ \\
\hline 0 & 33.41 \\
\hline 100 & 60.18 \\
\hline 200 & 63.42 \\
\hline 400 & 83.47 \\
\hline 600 & 83.64 \\
\hline 800 & 93.66 \\
\hline 1000 & 104.96 \\
\hline
\end{tabular}

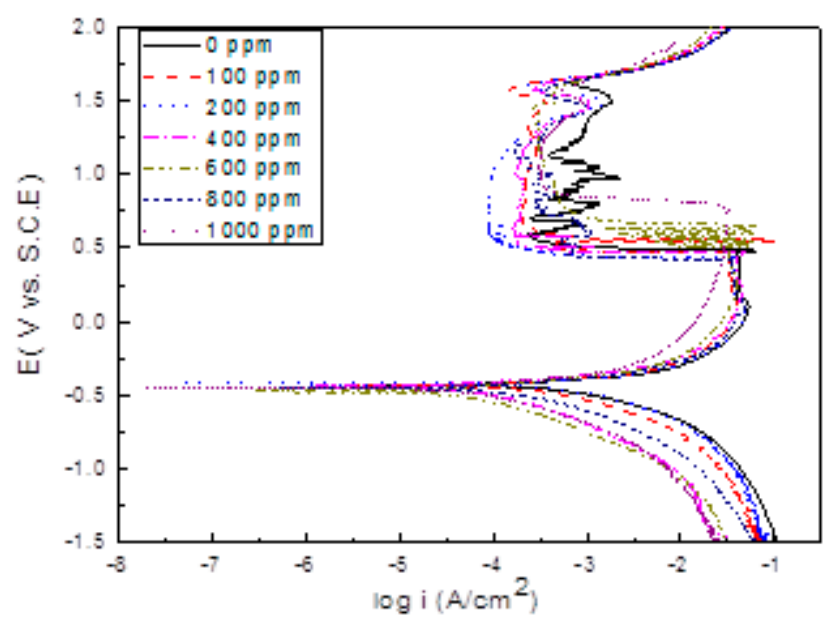

Figure 5. Effect of $\alpha$-linolenic acid concentration in the polarization curves for 1018 carbon steel in $0.5 \mathrm{M} \mathrm{H}_{2} \mathrm{SO}_{4}$. 
Table 2. Electrochemical parameters obtained from polarization curves.

\begin{tabular}{|c|c|c|c|c|c|c|c|}
\hline $\begin{array}{c}\mathrm{C}_{\mathrm{inh}} \\
(\mathrm{ppm})\end{array}$ & $\begin{array}{l}E_{\text {corr }} \\
(m V)\end{array}$ & $\begin{array}{c}I_{\text {corr }} \\
\left(\mathrm{mA} / \mathrm{cm}^{2}\right)\end{array}$ & $\begin{array}{c}\beta_{\mathrm{a}} \\
(\mathrm{mV} / \mathrm{dec})\end{array}$ & $\begin{array}{c}\beta_{\mathrm{c}} \\
(\mathrm{mV} / \mathrm{dec})\end{array}$ & $\begin{array}{c}I_{\text {pas }} \\
\left(\mathrm{mA} / \mathrm{cm}^{2}\right)\end{array}$ & $\begin{array}{c}R_{p} \\
(\mathrm{Ohm} \\
\left.\mathrm{cm}^{2}\right)\end{array}$ & $\begin{array}{l}\text { I.E. } \\
\text { (\%) }\end{array}$ \\
\hline 0 & -428 & 5.49 & 42 & -88 & 0.30 & 18 & - \\
\hline 100 & -451 & 4.89 & 38 & -140 & 0.29 & 75 & 24 \\
\hline 200 & -423 & 1.58 & 45 & -160 & 0.08 & 106 & 75 \\
\hline 400 & -439 & 0.09 & 40 & -165 & 0.16 & 540 & 96 \\
\hline 600 & -473 & 0.05 & 50 & -190 & 0.25 & 594 & 97 \\
\hline 800 & -454 & 0.15 & 60 & -270 & 0.16 & 184 & 96 \\
\hline 1000 & -475 & 0.23 & 50 & -240 & 0.26 & 141 & 94 \\
\hline
\end{tabular}

Inhibitor efficiency also increased when increasing the inhibitor concentration, reaching its highest value when $600 \mathrm{ppm}$ of $\alpha$-linolenic acid was added, and it decreased with a further increase in the $\alpha$-linolenic acid concentration. Hermoso-Diaz et al. [37] obtained a maximum inhibitor efficiency of $99 \%$ with the addition of 1000 ppm of Salvia hispanica, whereas, in the present work, the maximum inhibitor efficiency was $97 \%$ but with the addition of less of the inhibitor, i.e., 600 ppm. As established in [37], $\alpha$-linolenic acid is one of the main compounds found in Salvia hispanica extract together with linoleic acid and quercetin. Thus, the higher efficiency obtained with the Salvia hispanica extract must be by a kind of synergistic effect of these components and not only to the effect of $\alpha$-linolenic acid. Thus, one of the goals of the present work, which was to determine whether or not the obtained inhibitor efficiency for Salvia hispanica extract was due to the presence of $\alpha$-linolenic acid within its structure has been reached, and it has been found that $\alpha$-linolenic acid is partially responsible for this inhibition efficiency. However, we must take into account that $\alpha$-linolenic acid is an expensive reagent and its inhibition efficiency is lower than that obtained with Salvia hispanica extract.

The passive current density value, $\mathrm{I}_{\text {pas }}$, was decreased in the same fashion, reaching its lowest value with the addition of $600 \mathrm{ppm}$, and it increased once again when the inhibitor concentration increased further. The pitting potential value, $\mathrm{E}_{\text {pit }}$, was marginally affected by the addition of the inhibitor, fluctuating between $1580-1640 \mathrm{mV}$, obtaining its highest value in the uninhibited solution. Finally, the cathodic Tafel slope was affected to a greater extent than the anodic Tafel slope by the addition of the inhibitor, indicating that the $\alpha$-linolenic acid acted as a mixed type of inhibitor, affecting both anodic and, mainly, the cathodic reaction, such as hydrogen evolution reaction, maybe by a blocking effect [54,55] since at low $\mathrm{pH}$ value, $\mathrm{H}^{+}$reduction is the dominant cathodic reaction because of the high $\mathrm{H}^{+}$concentration [56].

\subsection{EIS Measurements}

EIS measurements in the Nyquist and Bode formats for 1018 carbon steel with and without $\alpha$-linolenic acid are shown in Figure 6. Nyquist data, Figure 6a, display a single, depressed, capacitive-like semicircle at all the frequency values with its center at the real axis, indicating that the corrosion process is under charge transfer control. The fact that it is not a pure semicircle is due to the surface roughness during the corrosion process. When the inhibitor was added, the data still display a capacitive semicircle at high- and intermediate-frequency values followed by some kind of elongations, where the imaginary impedance remains constant, but the real part increases due to the accumulation of a layer of corrosion products on the steel surface [54]. The semicircle diameter increases as the inhibitor concentration increases, reaching its highest value at $600 \mathrm{ppm}$, decreasing its value with a further increase in the inhibitor concentration. On the other hand, the Bode diagrams, Figure $6 b$, show that the impedance increases with increasing the $\alpha$-linolenic acid concentration, reaching its highest value in a concentration of $600 \mathrm{ppm}$, and it decreases when the inhibitor concentration is further increased. The Bode diagrams in the angle phase format, Figure $6 \mathrm{~b}$, show only one peak around $500 \mathrm{~Hz}$ for the uninhibited solution, which indicates the absence of any protective layer in this case. However, when $\alpha$-linolenic 
acid is added into the solution, the phase angle starts to increase with the frequency, and it remains constant in a relatively wide range of frequency, especially with the addition of 400 or 600 ppm of the inhibitor. The presence of $\alpha$-linolenic acid molecules at the interface consequently brings an increase in the peak heights. All spectra indicate the presence of a time constant only. The fact that the angle phase remains constant in a wide frequency interval indicates the formation of a protective layer formed by the inhibitor and $\mathrm{Fe}^{2+}$ ions on the steel surface, forming metal-inhibitor complexes. This frequency interval where the angle phase remains constant decreases for inhibitor concentrations higher than $600 \mathrm{ppm}$, indicating that the formed protective layer loses its protectiveness, bringing an increase in the corrosion rate.
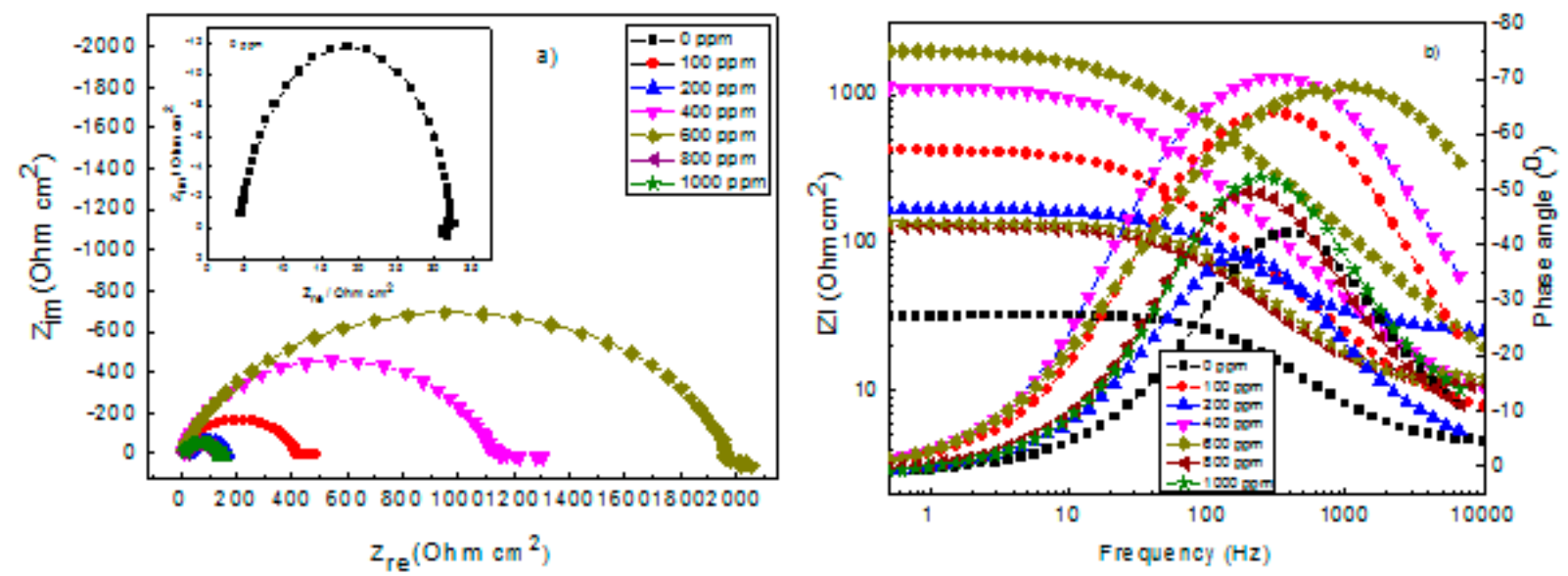

Figure 6. Effect of $\alpha$-linolenic acid concentration in the (a) Nyquist and (b) Bode diagrams for 1018 carbon steel in $0.5 \mathrm{M}$ $\mathrm{H}_{2} \mathrm{SO}_{4}$.

Equivalent electric circuits, such as those shown in Figure 7, are generally used to describe the process occurring at the metal-solution interface. In this figure, the solution resistance is represented by $R_{s}$, the charge transfer resistance by $R_{c t}$, the double-layer capacitance by $C_{d l}$, the film formed by the corrosion products resistance $R_{f}$ and $C_{f}$ its capacitance. However, to take into account dispersion effects due to surface heterogeneities such as surface roughness due to its dissolution, ideal capacitances are replaced by constant phase elements, CPE. Table 3 summarizes the electrochemical parameters obtained from the fitting by using electric circuits shown in Figure 7. From Table 3, it can be seen that the $R_{c t}$ value increases as the inhibitor concentration increases, reaching its highest value with the addition of $600 \mathrm{ppm}$, which is due to the adsorption of $\alpha$-linolenic acid to form a protective, passive layer, as shown by the polarization curves in Figure 5. A further increase in the $\alpha$-linolenic acid concentration brings a decrease in the $\mathrm{R}_{\mathrm{ct}}$ value. The $\mathrm{CPE}_{\mathrm{dl}}$ value, on the other side, decreases with an increase in the inhibitor concentration, reaching its lowest value at $600 \mathrm{ppm}$, increasing with a further increase in the inhibitor concentration. This decrease in the $C P E_{\mathrm{dl}}$ value is attributed to the replacement of the adsorbed water molecules at the metal surface by the inhibitor molecules [57] and forming a protective layer. The inhibitor efficiency increases with the $\alpha$-linolenic acid concentration, reaching its maximum value when $600 \mathrm{ppm}$ of the inhibitor is added to the electrolyte, and it decreases with a further increase in the $\alpha$-linolenic acid concentration similar to the results given by polarization curves in Figure 5. 
a)

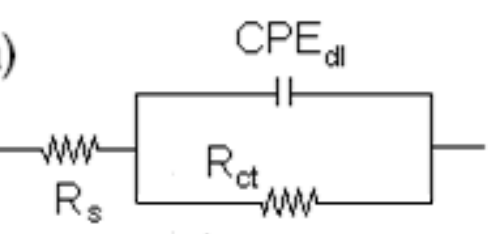

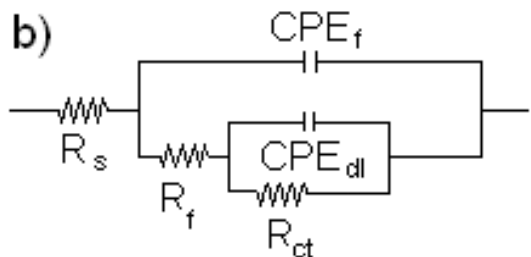

Figure 7. Equivalent electric circuits used to simulate EIS data for carbon steel in $0.5 \mathrm{M} \mathrm{H}_{2} \mathrm{SO}_{4}$ in the (a) absence and (b) presence of $\alpha$-linolenic acid.

Table 3. Electrochemical parameters used to simulate the EIS results.

\begin{tabular}{|c|c|c|c|c|c|c|}
\hline $\mathrm{C}_{\mathrm{inh}}(\mathrm{ppm})$ & $\underset{\left(\mathrm{Ohm} \mathrm{cm}^{2}\right)}{\mathbf{R}_{\mathrm{s}}}$ & $\begin{array}{c}\mathbf{R}_{\mathrm{ct}} \\
\left(\mathrm{Ohm} \mathrm{cm}^{2}\right)\end{array}$ & $\begin{array}{c}\mathrm{CPE}_{\mathrm{dl}} \\
\left(\mu \mathrm{F} \mathrm{cm}{ }^{2}\right)\end{array}$ & $\underset{\left(\mathrm{Ohm} \mathrm{\textrm {cm } ^ { 2 }}\right)}{\mathbf{R}_{\mathrm{f}}}$ & $\underset{\left(\mu \mathrm{F} \mathrm{cm} \mathrm{cm}^{2}\right)}{\mathrm{CPE}_{\mathrm{f}}}$ & I.E. (\%) \\
\hline 0 & 4 & 28 & $7.99 \times 10^{-5}$ & - & - & - \\
\hline 100 & 7 & 140 & $4.47 \times 10^{-5}$ & 15 & $8.47 \times 10^{-4}$ & 51 \\
\hline 200 & 8 & 420 & $2.57 \times 10^{-5}$ & 86 & $4.57 \times 10^{-4}$ & 78 \\
\hline 400 & 8 & 1130 & $1.13 \times 10^{-5}$ & 110 & $1.13 \times 10^{-4}$ & 97 \\
\hline 600 & 10 & 1960 & $7.08 \times 10^{-6}$ & 110 & $6.38 \times 10^{-5}$ & 98 \\
\hline 800 & 11 & 120 & $4.27 \times 10^{-5}$ & 50 & $3.27 \times 10^{-4}$ & 78 \\
\hline 1000 & 11 & 108 & $3.31 \times 10^{-5}$ & 20 & $6.31 \times 10^{-4}$ & 72 \\
\hline
\end{tabular}

It is generally accepted that the first step during the adsorption of an organic inhibitor on a metal surface usually involves the replacement of water molecules absorbed on the metal surface:

$$
\mathrm{Inh}_{\mathrm{sol}}+\mathrm{xH}_{2} \mathrm{O}_{\text {ads }} \rightarrow \mathrm{Inh}_{\mathrm{ads}}+\mathrm{xH}_{2} \mathrm{O}_{\text {sol }}
$$

The inhibitor may then combine with freshly generated $\mathrm{Fe}^{2+}$ ions on the steel surface, forming metal inhibitor complexes [58,59]:

$$
\begin{gathered}
\mathrm{Fe} \rightarrow \mathrm{Fe}^{2+}+2 \mathrm{e} \\
\mathrm{Fe}^{2+}+\mathrm{Inh}_{\mathrm{ads}} \rightarrow[\mathrm{Fe}-\mathrm{Inh}]_{\mathrm{ads}}{ }^{2+}
\end{gathered}
$$

The resulting complex, depending on its relative solubility, can either inhibit or catalyze further metal dissolution. At low concentrations, the amount of $\alpha$-linolenic acid is not enough to form a compact complex with the metal ions, so the resulting adsorbed intermediate will be readily soluble in the acidic environment. However, at relatively higher inhibitor concentrations, more $\alpha$-linolenic acid molecules become available for the complex formation, which subsequently diminishes the solubility of the surface layer, leading to improve the inhibition of metal corrosion. Thus, so far, it has been shown that the increase in the impedance modulus is due to the protective character of the $\alpha$-linolenic acid.

\subsection{Theoretical Calculations \\ Neutral Molecule}

In order to have a better understanding of the corrosion mechanism, some quantum chemical calculations to study the correlation between the molecular structure of this organic compound and its inhibition effect have been performed. Chemical parameters were discussed both in the aqueous phase. The optimized structure in its neutral state is shown in Figure 8. The molecule reactivity was investigated via analysis of the frontier molecular orbital. Electronic parameters are listed in Table 4. ELUMO indicates the propensity of the molecule to accept electrons. The lower the $\mathrm{E}_{\mathrm{LUMO}}$ value is, the greater is the ability of that molecule to accept electrons. The higher the $\mathrm{E}_{\mathrm{HOMO}}$ is, the greater is the ability of that molecule to donate electrons [60]. The gap $(\Delta \mathrm{E})$ is an important parameter that indicates the reactivity tendency of organic molecules toward the metal surface. As $\Delta \mathrm{E}$ decreases, the reactivity of the molecule increases, leading to an increase in its adsorption onto a metal surface. Normally, the lowest value of hardness is expected to have the highest inhibition ef- 
ficiency. The high values of the dipolar moment $(\mu)$ favor the accumulation of the inhibitor on the surface. The electrophilicity index, on the other hand, denotes the electron-accepting capability of a molecule [61]. HOMO is often associated with electron-donating species. As can be seen in Figure 9, the HOMO is distributed over the entire chain of carbon atoms, and consequently, the calculated values of the Hirsfeld charges (Table 5) on hetero-atoms indicate that carbon atom number 10 is the prominent site for the electrophilic adsorption. Likewise, LUMO indicates its ability to accept electrons that are located in the carboxyl functional group. The orbitals map is shown in Figure 10. On the other hand, Table 5 shows that some of the results obtained of the condensed Fukui, where the nucleophilic attack $\left(f_{\mathrm{K}}^{+}\right)$value is in the atom $18 \mathrm{C}$, whereas electrophilic attack $\left(f_{\mathrm{K}}{ }^{-}\right)$is located in the atom $10 \mathrm{C}$, Figure 11a, which is in agreement with the distribution of electronic density in HOMO and LUMO, respectively. Consequently, the local softness for electrophilic $\left(S_{\mathrm{k}}{ }^{-}\right)$ and nucleophilic attacks $\left(S_{\mathrm{k}}{ }^{+}\right)$, as well as the local philicity for electrophilic $\left(\omega_{\mathrm{k}}{ }^{-}\right)$and nucleophilic attacks $\left(\omega_{\mathrm{k}}{ }^{+}\right)$, have been calculated for each atom in the molecule. According to these results, the highest value of $S_{\mathrm{k}}{ }^{+}$is for atom 7C (0.1505) and $S_{\mathrm{k}}{ }^{-}$is for atom 10C (0.1862) and belongs to the double-bound $\mathrm{C}=\mathrm{C}$ in the same way the highest $\omega_{\mathrm{k}}{ }^{+}$and $\omega_{\mathrm{k}}{ }^{-}$ values are 0.1335 in $7 \mathrm{C}$ atom and 0.1653 in $10 \mathrm{C}$ atom, respectively. The optimized structure $\alpha$-linolenic acid contains an active center for protonation. According to $f_{\mathrm{K}}{ }^{-}, S_{\mathrm{K}}{ }^{-}$and $\omega_{\mathrm{k}}{ }^{-}$, the atom most susceptible to an electrophilic attack is $10 \mathrm{C}$ in all cases, being the most prominent site for electrophilic adsorption. While the prominent site for adsorption (nucleophilic) according to $f_{\mathrm{k}}{ }^{+}$is $18 \mathrm{C}$ atom, and in $\mathrm{S}_{\mathrm{k}}{ }^{+}, \omega_{\mathrm{k}}{ }^{+}$is $7 \mathrm{C}$ atom. The graphic of the local softness and philicity for the electrophilic attack $\left(S_{\mathrm{k}}{ }^{-}, \omega_{\mathrm{k}}{ }^{-}\right)$and nucleophilic attack $\left(S_{\mathrm{k}}{ }^{+}, \omega_{\mathrm{k}}{ }^{+}\right)$of $\alpha$-linolenic acid is presented in Figure 11.

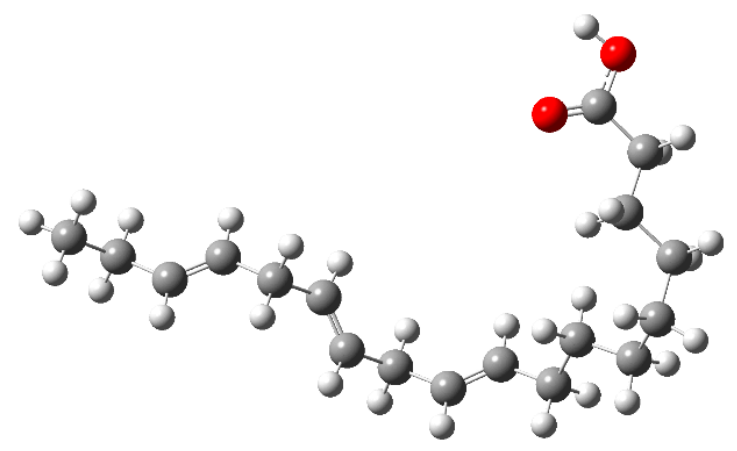

Figure 8. Optimized structure of the $\alpha$-linoleic acid in the aqueous phase.

Table 4. Calculated quantum chemical parameters for the neutral $\alpha$-linolenic acid molecule.

\begin{tabular}{|c|c|}
\hline Chemical Properties & Values \\
\hline $\mathrm{E}_{\text {HOMO }}$ (Hartree) & -0.23646 \\
\hline ELUMO (Hartree) & -0.00920 \\
\hline $\mathrm{E}_{\mathrm{HOMO}}(\mathrm{eV})$ & -6.43440 \\
\hline $\mathrm{E}_{\text {LUMO }}(\mathrm{eV})$ & -0.25034 \\
\hline $\mathrm{GAP}(\mathrm{eV})$ & 6.1841 \\
\hline Electronegativity (eV) & 3.1 \\
\hline Hardness (eV) & 3.29 \\
\hline Ionization Potential (eV) & 6.39 \\
\hline Dipole Moment & 1.9342 \\
\hline Electrophilicity & 1.46 \\
\hline Electron Affinity (eV) & -0.19 \\
\hline
\end{tabular}




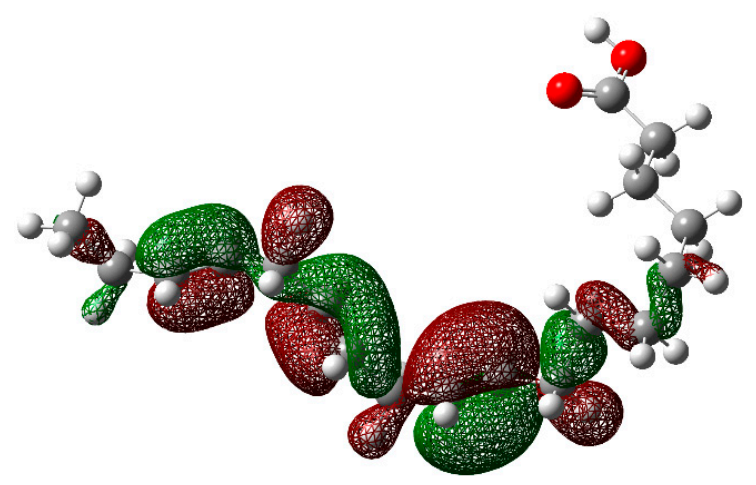

Figure 9. The highest occupied molecular orbital (HOMO) of $\alpha$-linoleic acid in the aqueous phase.

Table 5. Fukui functions, local softness, philicity, dual Fukui functions, dual local softness and dual local philicity for neutral $\alpha$-linoleic acid molecule with Hirsfeld charges.

\begin{tabular}{ccclcclccc}
\hline Atom & $f_{\mathbf{k}}{ }^{+}$ & $f_{\mathbf{k}}{ }^{-}$ & \multicolumn{1}{c}{$\boldsymbol{\Delta} \boldsymbol{f}_{\mathbf{k}}$} & $\boldsymbol{S}_{\mathbf{k}}{ }^{+}$ & $\boldsymbol{S}_{\mathbf{k}}{ }^{-}$ & \multicolumn{1}{c}{$\boldsymbol{\Delta} \boldsymbol{S}_{\mathbf{k}}$} & $\boldsymbol{\omega}_{\mathbf{k}}{ }^{+}$ & $\boldsymbol{\omega}_{\mathbf{k}}{ }^{-}$ & $\boldsymbol{\Delta} \boldsymbol{\omega}_{\mathbf{k}}$ \\
\hline 3C & 0.0586 & 0.0680 & 0.0094 & 0.0964 & 0.1119 & 0.0155 & 0.0855 & 0.0993 & 0.0138 \\
4C & 0.0475 & 0.0612 & 0.0137 & 0.0781 & 0.1006 & 0.0225 & 0.0693 & 0.0893 & 0.0199 \\
7C & 0.0915 & 0.0592 & -0.0323 & 0.1505 & 0.0973 & -0.0532 & 0.1336 & 0.0864 & -0.0472 \\
9C & 0.0477 & 0.1083 & 0.0605 & 0.0785 & 0.1781 & 0.0996 & 0.0697 & 0.1581 & 0.0884 \\
10C & 0.0586 & 0.1133 & 0.0547 & 0.0964 & 0.1863 & 0.0899 & 0.0856 & 0.1653 & 0.0798 \\
11C & 0.0103 & 0.0210 & 0.0107 & 0.0169 & 0.0345 & 0.0176 & 0.0150 & 0.0306 & 0.0156 \\
18C & 0.0475 & 0.0002 & -0.0473 & 0.0782 & 0.0004 & -0.0778 & 0.0694 & 0.0003 & -0.0691 \\
19O & 0.0428 & 0.0001 & -0.0426 & 0.0703 & 0.0002 & -0.0701 & 0.0624 & 0.0002 & -0.0623 \\
20O & 0.0236 & 0.0004 & -0.0232 & 0.0389 & 0.0006 & -0.0382 & 0.0345 & 0.0006 & -0.0339 \\
\hline
\end{tabular}

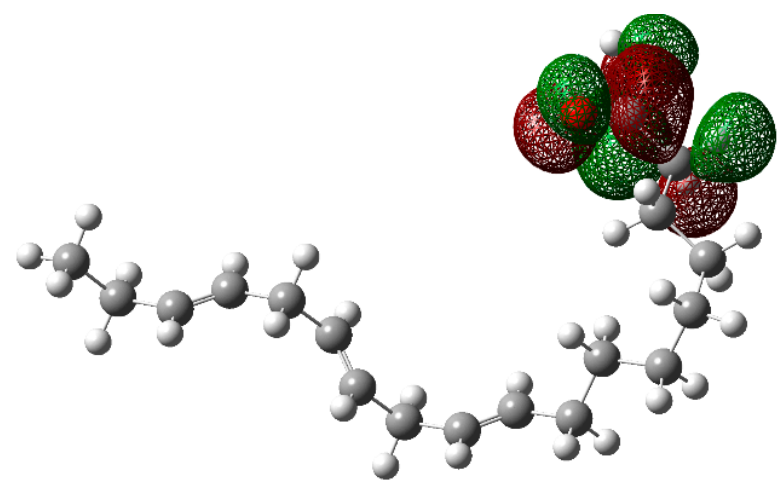

Figure 10. The lowest unoccupied molecular orbital (LUMO) of $\alpha$-linoleic acid in the aqueous phase. 

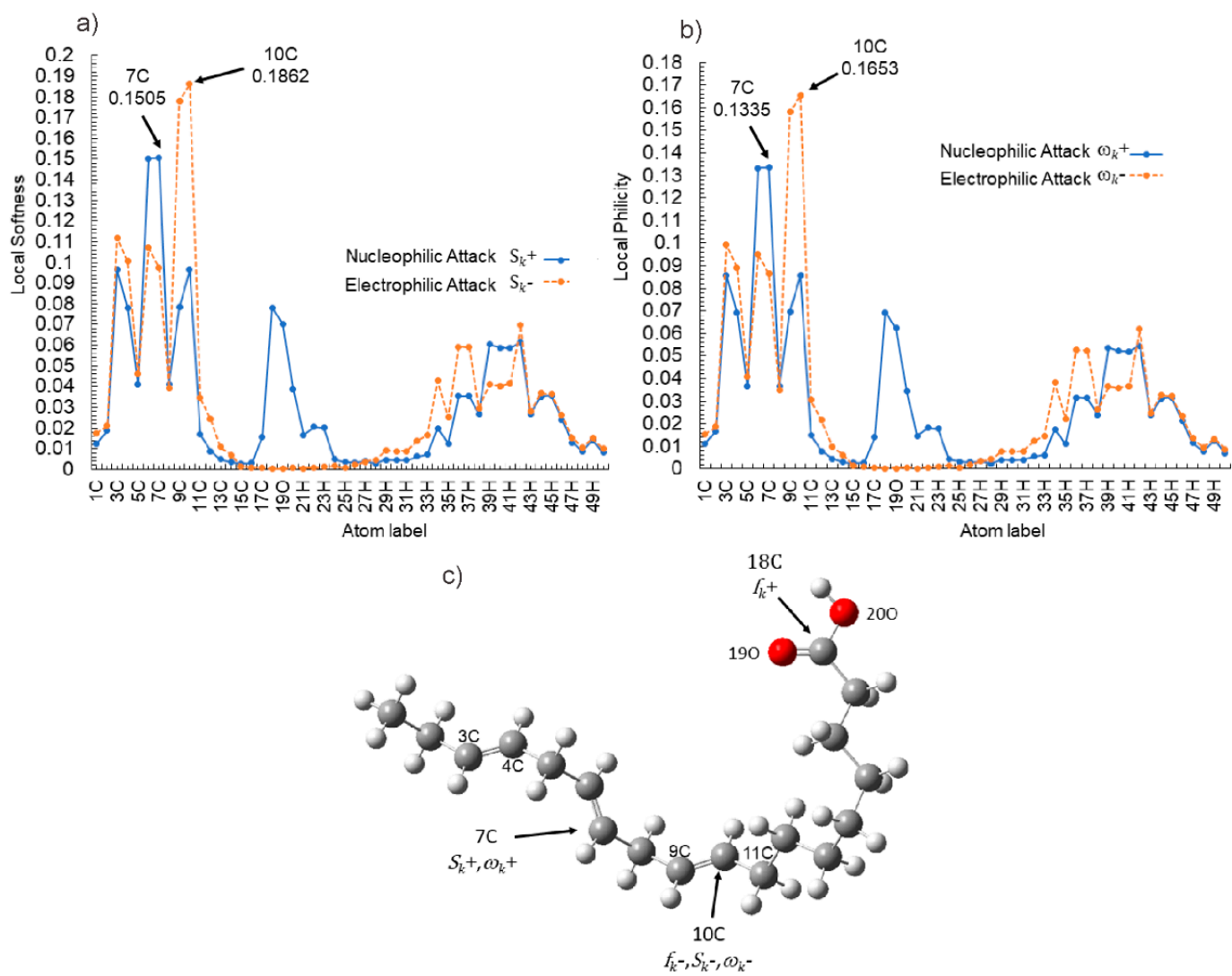

Figure 11. Graphical representation of the local dual descriptors nucleophilic and electrophilic attack (a) local softness $S_{\mathrm{k}}{ }^{+}$, $S_{\mathrm{k}}{ }^{-},(\mathbf{b})$ local philicity $\omega_{\mathrm{k}}{ }^{+}, \omega_{\mathrm{k}}{ }^{-}$and (c) nucleophilic and electrophilic attack on hetero-atoms for the neutral $\alpha$-linolenic acid using the Fukui function, local softness and local philicity.

The results of the dual Fukui function $\left(\Delta f_{\mathrm{k}}\right)$, the dual local softness $\left(\Delta S_{\mathrm{k}}\right)$, and the dual local philicity $\left(\Delta \omega_{\mathrm{k}}\right)$ are summarized in Table 5. The most representative active sites of de descriptors $\left(\Delta f_{\mathrm{k}}, \Delta S_{\mathrm{k}}\right.$ and $\left.\Delta \omega_{\mathrm{k}}\right)$ are shown in Figure 12. According to Hsissou et al., the dual descriptors with values lower than zero have the ability to accept electrons from the metal, while those with values higher than zero suggest electrophilic centers [50]. The most active sites for electron-accepting centers for neutral $\alpha$-linoleic acid decreases in the following order: $18 \mathrm{C}>19 \mathrm{C}>20 \mathrm{C}$, whereas, in the active sites donation, the decreasing order is: $9 \mathrm{C}>10 \mathrm{C}>4 \mathrm{C}>3 \mathrm{C}>11 \mathrm{C}$.

The presence of the alkene functional group $(C=C)$ in the structure of $\alpha$-linolenic acid provides a high tendency towards its protonation in an aqueous acidic medium. Therefore, it is important to analyze the structures in their protonated form [61]. According to local descriptors, Figure 11, the most susceptible atom to an electrophilic attack $\left(f_{\mathrm{k}}{ }^{-}\right.$, $\left.S_{\mathrm{k}}{ }^{-}, \omega_{\mathrm{k}}{ }^{-}\right)$, on the $\alpha$-linolenic acid is the atom 10C, which corresponds to a $\mathrm{C}=\mathrm{C}$ bond. Because protonation is the addition of a proton $\left(\mathrm{H}^{+}\right)$to an atom, molecule, or ion, it was determined that atom $10 \mathrm{C}$ will be the site to be protonated [62]. Electronic parameters of the protonated inhibitor molecule and its optimized structure can be seen in Table 6 and Figure 13, respectively. A comparison of the quantum chemical calculations for neutral and protonated molecules indicates that there is a clear correlation. $\mathrm{E}_{\mathrm{LUMO}}$ indicates the propensity of the molecule to accept electrons. The lower $E_{L U M O}$ is, the greater is the ability of that molecule to accept electrons. However, active sites for donating or accepting electrons changed with respect to the neutral molecule. The electron clouds in both HOMO and LUMO occupy similar areas, as can be seen in Figures 14 and 15, respectively. Some values with the Fukui functions, local softness and local philicity are shown in Table 7 . The prominent site for the electrophilic adsorption according to $f_{\mathrm{k}}{ }^{-}, \mathrm{S}_{\mathrm{k}}{ }^{-}, \omega_{\mathrm{k}}{ }^{-}$is in atom $3 \mathrm{C}$; 
likewise, the prominent site for the adsorption (nucleophilic) in $f_{\mathrm{k}}{ }^{+}$is atom $8 \mathrm{C}$, and in $\mathrm{S}_{\mathrm{k}}{ }^{+}$, $\omega_{\mathrm{k}}{ }^{+}$is atom $5 \mathrm{C}$ (See Figure 16).
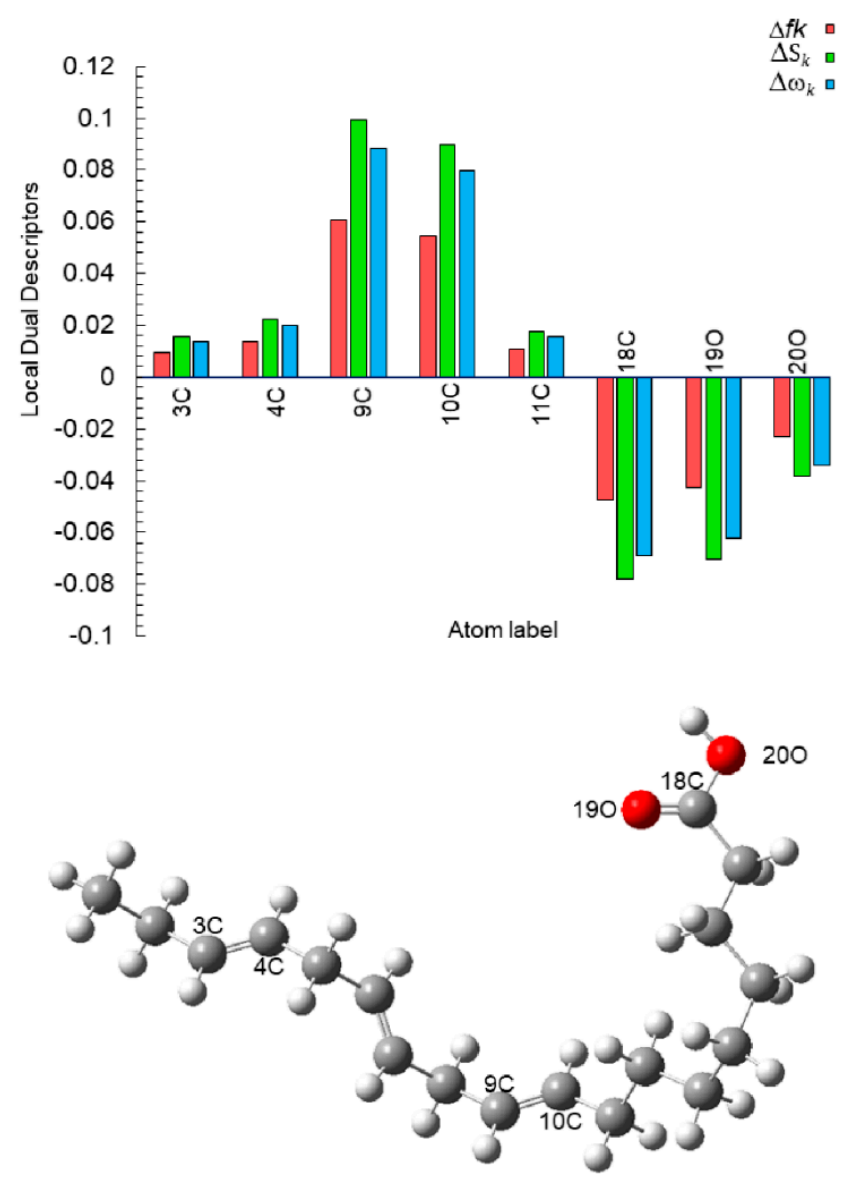

Figure 12. Graphical representation of the dual descriptors $\left(\Delta f_{\mathrm{k}}, \Delta S_{\mathrm{k}}\right.$ and $\left.\Delta \omega_{\mathrm{k}}\right)$ for the most active sites of neutral $\alpha$-linoleic acid molecule.

Table 6. Calculated quantum chemical parameters for the protonated $\alpha$-linolenic acid molecule.

\begin{tabular}{cc}
\hline Chemical Properties & Values \\
\hline E HOMO $_{\text {Hartree })}$ & -0.26663 \\
\hline E $_{\text {LUMO }}($ Hartree $)$ & -0.12105 \\
\hline E $_{\text {HOMO }}(\mathrm{eV})$ & -7.25537 \\
\hline $\mathrm{E}_{\mathrm{LUMO}}(\mathrm{eV})$ & -3.29393 \\
\hline GAP $(\mathrm{eV})$ & 3.961 \\
\hline Electronegativity $(\mathrm{eV})$ & 5.30 \\
\hline Hardness $(\mathrm{eV})$ & 1.95 \\
\hline Ionization Potential $(\mathrm{eV})$ & 7.26 \\
\hline Dipole Moment & 9.1693 \\
\hline Electrophilicity & 7.20 \\
\hline Electron Affinity $(\mathrm{eV})$ & 3.35 \\
\hline
\end{tabular}




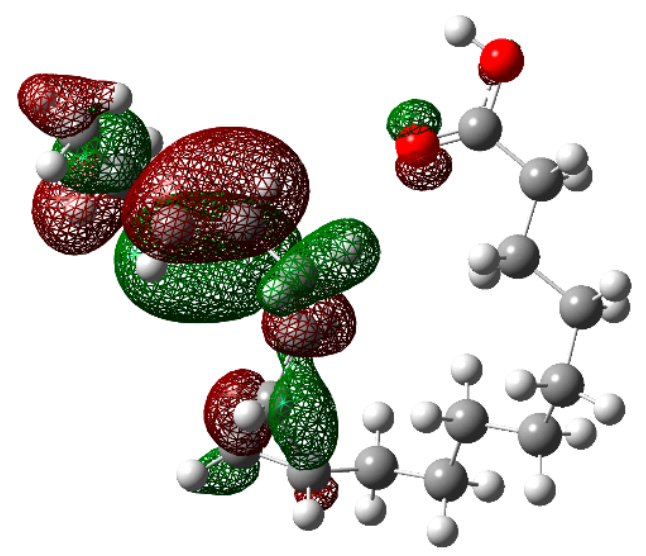

Figure 13. The highest occupied molecular orbital (HOMO) for the protonated $\alpha$-linoleic acid in the aqueous phase.

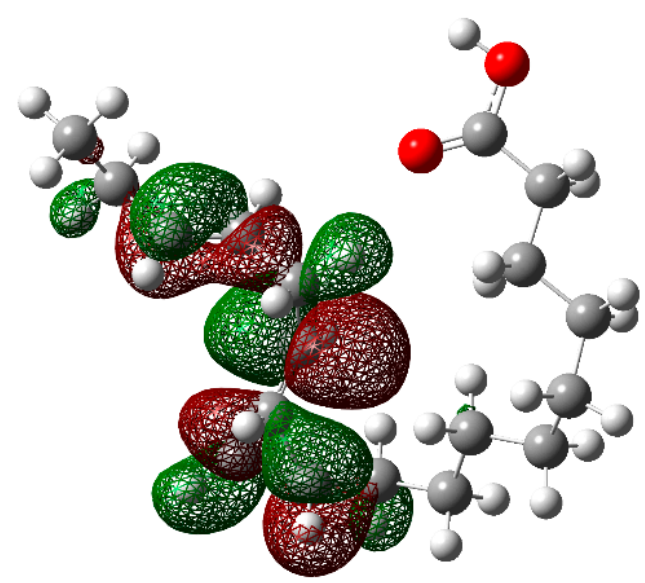

Figure 14. The lowest unoccupied molecular orbital (LUMO) for the protonated $\alpha$-linoleic acid in the aqueous phase.

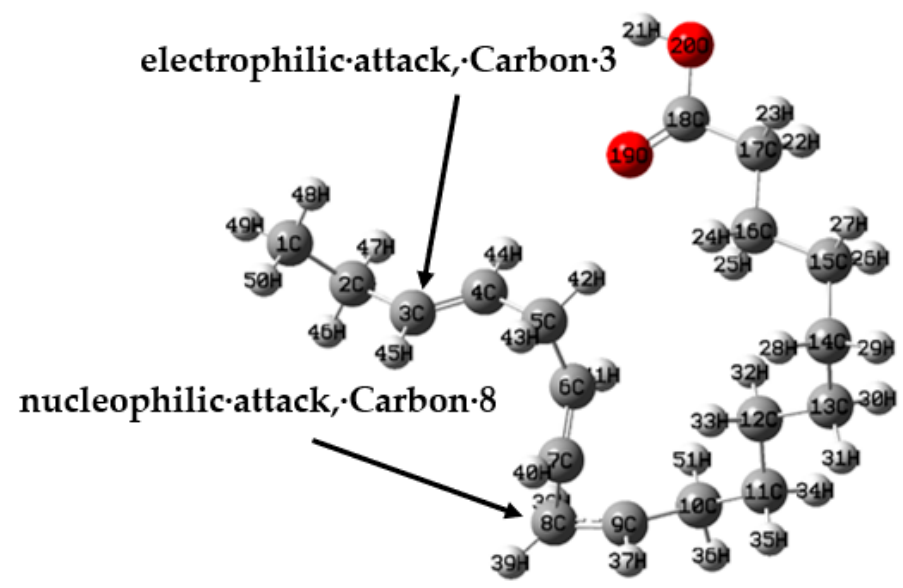

Figure 15. The nucleophilic and electrophilic attack in the protonated $\alpha$-linoleic acid molecule using the Fukui function. 
Table 7. Fukui functions, local softness, local philicity, dual Fukui functions, dual local softness and dual local philicity for the protonated $\alpha$-linoleic acid molecule with Hirsfeld charges.

\begin{tabular}{cccccccccc}
\hline Atom & $f_{\mathbf{k}}{ }^{+}$ & $f_{\mathbf{k}}{ }^{-}$ & \multicolumn{1}{c}{$\boldsymbol{\Delta} \boldsymbol{f}_{\mathbf{k}}$} & $\boldsymbol{S}_{\mathbf{k}}{ }^{+}$ & $\boldsymbol{S}_{\mathbf{k}}{ }^{-}$ & \multicolumn{1}{c}{$\boldsymbol{\Delta} \boldsymbol{S}_{\mathbf{k}}$} & $\boldsymbol{\omega}_{\mathbf{k}}{ }^{+}$ & $\boldsymbol{\omega}_{\mathbf{k}}{ }^{-}$ & $\Delta \omega_{\mathbf{k}}$ \\
\hline 2C & 0.0572 & 0.1610 & 0.1038 & 0.0940 & 0.2648 & 0.1708 & 0.0835 & 0.2350 & 0.1515 \\
3C & 0.0220 & 0.1777 & 0.1557 & 0.0362 & 0.2923 & 0.2561 & 0.0321 & 0.2594 & 0.2273 \\
5C & 0.1937 & 0.0133 & -0.1804 & 0.3187 & 0.0219 & -0.2968 & 0.2829 & 0.0195 & -0.2634 \\
7C & 0.0720 & 0.0222 & -0.0498 & 0.1185 & 0.0366 & -0.0819 & 0.1052 & 0.0325 & -0.0727 \\
8C & 0.0809 & 0.0175 & -0.0634 & 0.1331 & 0.0288 & -0.1043 & 0.1181 & 0.0256 & -0.0925 \\
18C & -0.0004 & 0.0432 & 0.0436 & -0.0007 & 0.0710 & 0.0717 & -0.0006 & 0.0630 & 0.0636 \\
40H & 0.0594 & 0.0121 & -0.0473 & 0.0977 & 0.0199 & -0.0779 & 0.0867 & 0.0176 & -0.0691 \\
44H & 0.0206 & 0.0495 & 0.0290 & 0.0338 & 0.0815 & 0.0476 & 0.0300 & 0.0723 & 0.0423 \\
45H & 0.0156 & 0.0477 & 0.0321 & 0.0257 & 0.0785 & 0.0528 & 0.0228 & 0.0697 & 0.0469 \\
\hline
\end{tabular}

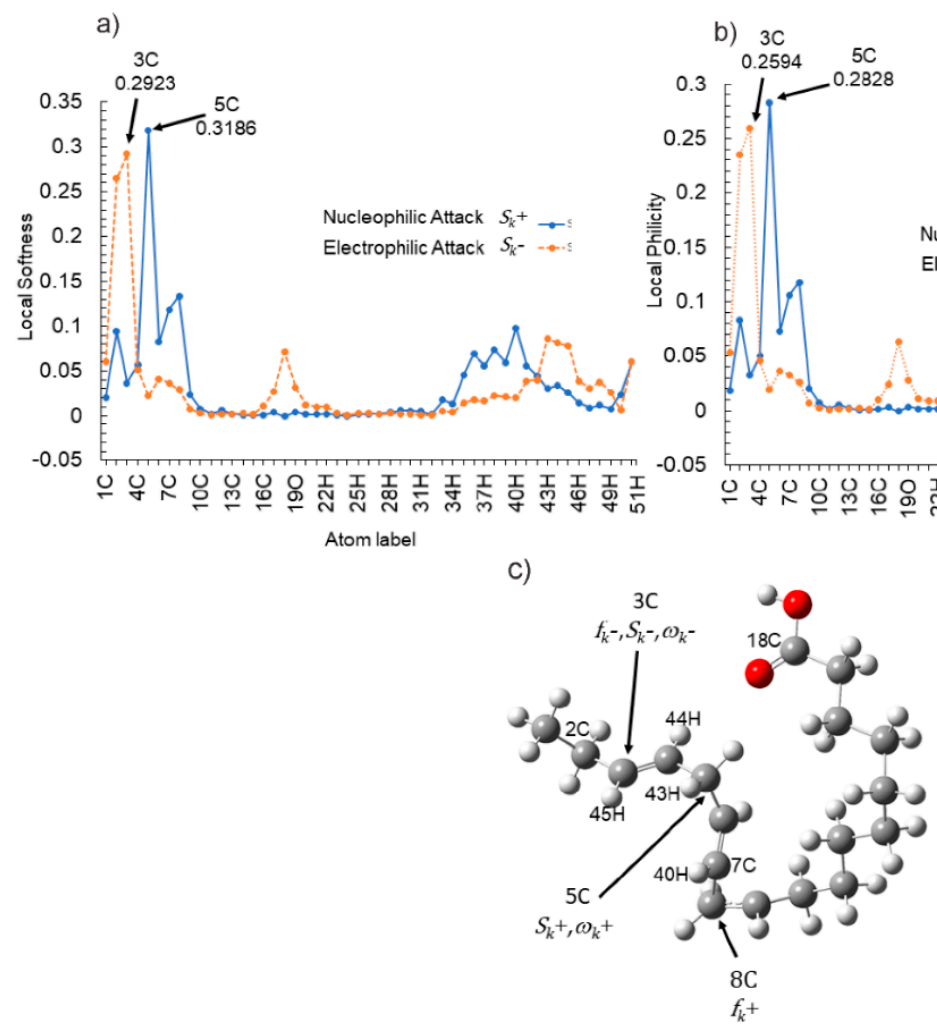

Figure 16. Graphical representation of the local dual descriptors nucleophilic attack and electrophilic attack (a) local softness $S_{\mathrm{k}}{ }^{+}, S_{\mathrm{k}}{ }^{-},(\mathbf{b})$ local philicity $\omega_{\mathrm{k}}{ }^{+}, \omega_{\mathrm{k}}{ }^{-}$and (c) nucleophilic and electrophilic attack on hetero-atoms for the protonated $\alpha$-linolenic acid using the Fukui function, local softness and local philicity.

The values of the dual Fukui function $\left(\Delta f_{\mathrm{k}}\right)$, the dual local softness $\left(\Delta S_{\mathrm{k}}\right)$ and the dual local philicity $\left(\Delta \omega_{\mathrm{k}}\right)$ are shown in Table 7 . The active sites for electron-accepting from metal centers in the protonated linoleic acid decreases in the following order: $5 \mathrm{C}>8 \mathrm{C}>7 \mathrm{C}$ $>40 \mathrm{H}$, and the active sites for electron-donating from metal centers in decreasing order is: $3 \mathrm{C}>2 \mathrm{C}>18 \mathrm{C}>43 \mathrm{HC}>45 \mathrm{H}>44 \mathrm{H}$. See Figure 17 . 

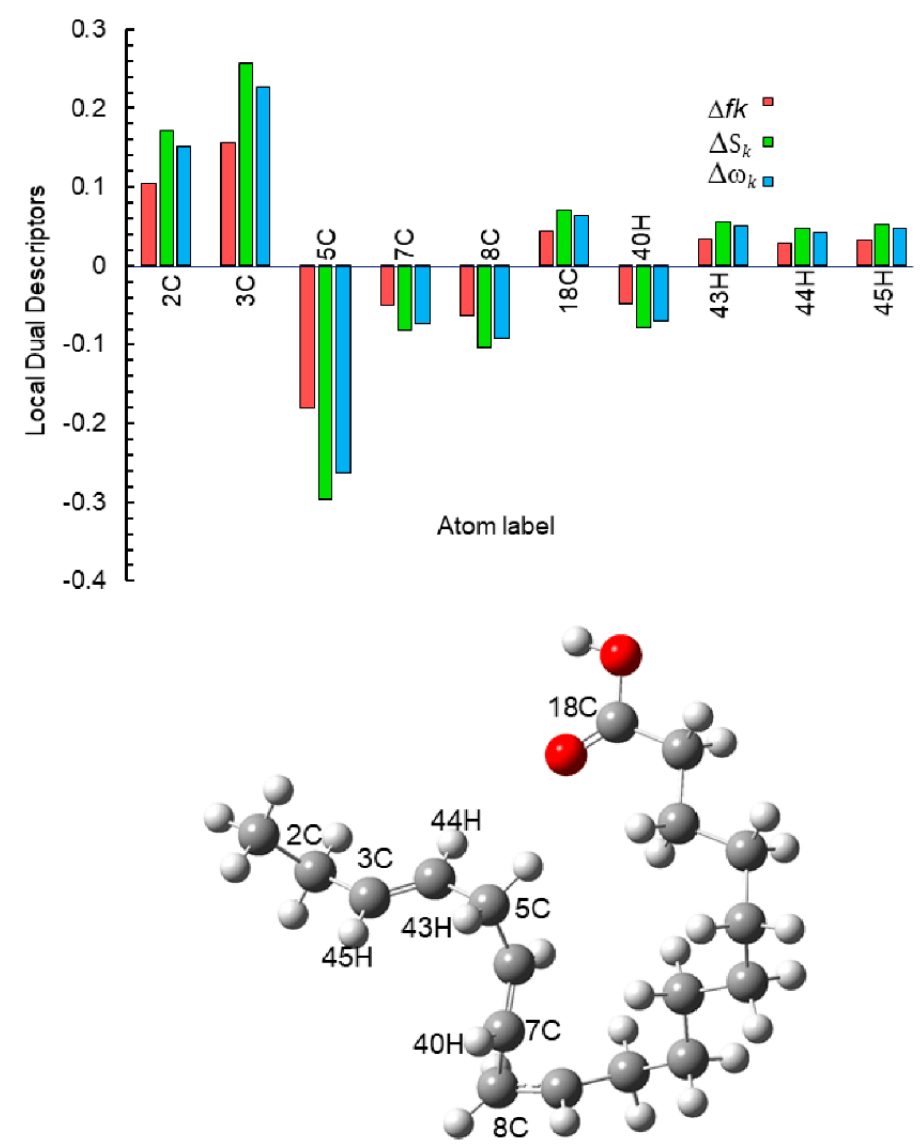

Figure 17. Graphical representation of the dual descriptors $\left(\Delta f_{\mathrm{k}}, \Delta S_{\mathrm{k}}\right.$ and $\left.\Delta \omega_{\mathrm{k}}\right)$ for the most active sites of the protonated $\alpha$-linoleic acid molecule.

In summary, according to Guo et al. [63], molecules that have back-donation at their carbon atoms are those where the electron density moves along the structure from HOMO to LUMO. According to these results, one could conclude that neutral $\alpha$-linoleic acid will have some active centers (nucleophilic and electrophilic) to interact with the steel surface. In contrast to protonated $\alpha$-linoleic acid, the electron density in both HOMO and LUMO is in the same part of the structure where $f_{\mathrm{K}}{ }^{\alpha}, S_{\mathrm{k}}{ }^{\alpha}$ and $\omega_{\mathrm{k}}{ }^{\alpha}$ allowed us to distinguish the atoms susceptible to both electrophilic and nucleophilic attack in the steel surface. Additionally, the local dual descriptors allow us to identify the active sites for electron-accepting and electron-donating in neutral and protonated states.

\subsection{Corrosion Inhibition Mechanism}

In order to try to explain the way that $\alpha$-linolenic acid is adsorbed onto 1018 carbon steel and inhibits its dissolution, a scheme shown in Figure 18 will be used.

Based on the chemical structure for $\alpha$-linolenic acid given in Figure 1, it can be seen that it contains a hydrophilic and a hydrophobic part within its structure. As it is known, when an $\mathrm{H}^{+}$atom is attached to a $\mathrm{C}$ in a ring contained in an inhibitor, it improves its inhibition efficiency since it could form - $\mathrm{CHO}$ or - $\mathrm{COOH}$ groups [64]. Based on the latter, $\alpha$-linolenic acid has a carboxyl group - $\mathrm{COOH}$ in its structure that corresponds to the hydrophilic part. The hydrophobic side corresponds to the carbon chain in the $\alpha$-linolenic acid, which, as was explained, in the presence of $\mathrm{H}^{+}$, could result in $-\mathrm{CHO}$ or $-\mathrm{COOH}$ groups. 


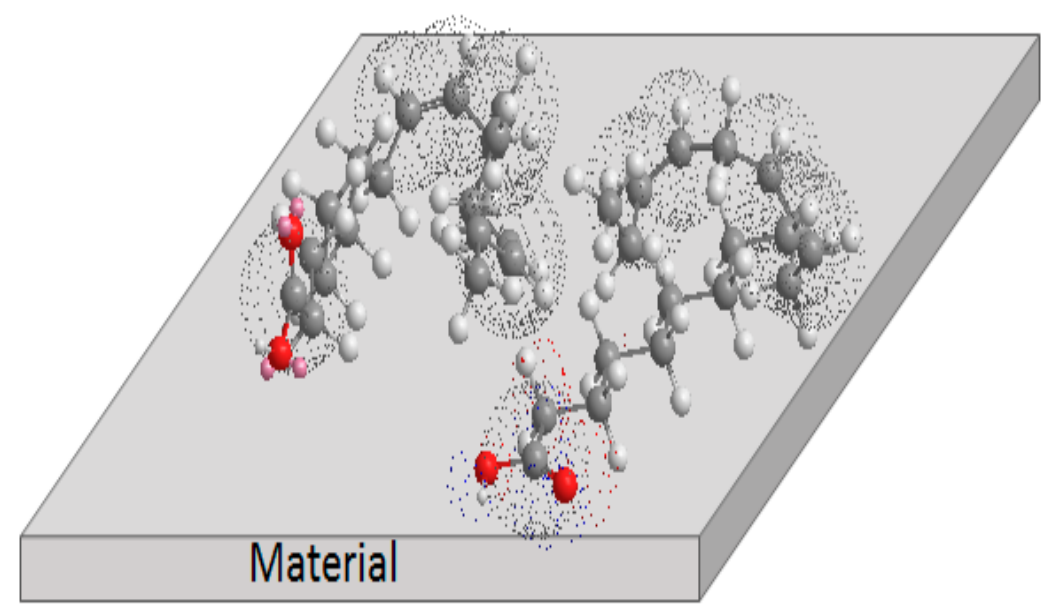

Figure 18. Adsorption process of $\alpha$-linolenic acid on steel surface.

The carboxylic group is adsorbed on the metal surface to occupy one adsorption site. This adsorption is preferable by an electronic interaction between the unshared electrons pairs from the heteroatoms or the $\pi$ orbitals bond from the molecule, with the $d$ orbitals on the metallic surface. The alkyl chain is adsorbed on the surface of the material through the $\pi$ orbitals of the unsaturation.

\section{Conclusions}

This research has shown that $\alpha$-linolenic acid turned out to be an efficient corrosion inhibitor for carbon steel in $0.5 \mathrm{M} \mathrm{H}_{2} \mathrm{SO}_{4}$, with its efficiency increasing with an increase in its concentration up to $600 \mathrm{ppm}$, but it decreases with a further increase in its concentration. Polarization curves have shown that $\alpha$-linolenic acid is a good, mixed type of inhibitor with a stronger effect on the cathodic hydrogen evolution electrochemical reactions. This is because $\alpha$-linolenic acid is chemically adsorbed onto the steel surface according to a Langmuir adsorption isotherm to form a layer of protective corrosion products. It decreased not only the corrosion current density but also the passivation current density value. EIS measurements indicated that the corrosion process was under charge transfer control. DFT calculations indicated a high tendency of $\alpha$-linolenic acid to donate electrons and that it can be easily protonated in its $\mathrm{O}$ atoms, which act as possible adsorption centers of the inhibitor. This was corroborated because, in acidic environments, it had the highest $\mathrm{E}_{\mathrm{HUMO}}$ value, the best chemical reactivity, the greatest tendency to transfer electrons and a greater facility of modifying its electronic configuration in the presence of carbon steel specimens according to its chemical hardness value. This explained why $\alpha$-linolenic acid was more efficient in an acidic environment than in a neutral one.

Author Contributions: I.A.H.-D., investigation and methodology; R.L.-C., resources and conceptualization; J.P.F.-D.1.R., formal analysis and writing-review; E.S.-B., data curation and supervision; L.L.L.-M., software and writing-original draft preparation; J.G.G.-R., project administration and resources; J.U.-C., funding acquisition and project administration. All authors have read and agreed to the published version of the manuscript.

Funding: This research received no external funding.

Institutional Review Board Statement: Not applicable.

Informed Consent Statement: Not applicable.

Data Availability Statement: The data presented in this study are available on request from the corresponding author.

Conflicts of Interest: The authors declare no conflict of interest. 


\section{References}

1. Qiu, L.G.; Wu, Y.; Wang, Y.M.; Jiang, X. Synergistic effect between cationic gemini surfactant and chloride ion for the corrosion inhibition of steel in sulphuric acid. Corros. Sci. 2008, 50, 576-582. [CrossRef]

2. Li, Y.; Xin, Y.; Wang, X.; Li, S. Fixed Bed Reactor Pyrolysis of Rape Straw: Effect of Dilute Acid Pickling on the Production of Bio-oil and Enhancement of Sugars. Ind. Eng. Chem. Res. 2020, 59, 17564-17574. [CrossRef]

3. El Kacimi, Y.; Touir, R.; Galai, M.; Alaoui, K.; Dkhireche, N.; Touhami, M.E. Relationship between silicon, phosphorus content and grain number in mild steels and its corrosion resistance in pickling hydrochloric acid. Int. J. Ind. Chem. 2020, 11, 111-122 [CrossRef]

4. Prasad, A.R.; Kunyankandy, A.; Joseph, A. Economic Considerations. In Corrosion Inhibition in the Oil and Gas Industry; Saji, V.S., Umoren, S.A., Eds.; Wiley-VCH Verlag GmbH and Co.: Weinheim, Germany, 2020.

5. Dohare, P.; Quraishi, M.A.; Verma, C.; Lgaz, H.; Salghi, R.; Ebenso, E.E. Ultrasound induced green synthesis of pyrazolo-pyridines as novel corrosion inhibitors useful for industrial pickling process: Experimental and theoretical approach. Results Phys. 2020, 13, 102344. [CrossRef]

6. Shetty, P. Schiff bases: An overview of their corrosion inhibition activity in acid media against mild steel. Chem. Eng. Commun. 2020, 207, 985-1029. [CrossRef]

7. Mohammed, N.J.; Othman, N.K.; Taib, M.F.M.; Samat, M.H.; Yahya, S. Experimental and Theoretical Studies on Extract of Date Palm Seed as a Green Anti-Corrosion Agent in Hydrochloric Acid Solution. Molecules 2021, 26, 3535. [CrossRef]

8. Savita, N.C.; Qurashi, A.; Chauhan, D.S.; Quraishi, M.A. Frontiers and advances in green and sustainable inhibitors for corrosion applications: A critical review. J. Mol. Liq. 2020, 321, 114385.

9. Varvara, S.; Caniglia, G.; Izquierdo, J.; Bostan, R.; Găină, L.; Bobis, O.; Souto, R.M. Multiscale electrochemical analysis of the corrosion control of bronze in simulated acid rain by horse-chestnut (Aesculus hippocastanum L.) extract as green inhibitor. Corros. Sci. 2020, 165, 108381. [CrossRef]

10. Feng, L.; Zhang, S.; Qiang, Y.; Xu, S.; Tan, B.; Chen, S. The synergistic corrosion inhibition study of different chain lengths ionic liquids as green inhibitors for X70 steel in acidic medium. Mater. Chem. Phys. 2018, 215, 229-241. [CrossRef]

11. Luo, X.; Ci, C.; Li, J.; Lin, K.; Du, S.; Zhang, H.; Li, X.; Cheng, Y.F.; Zang, J.; Liu, Y. 4-aminoazobenzene modified natural glucomannan as a green eco-friendly inhibitor for the mild steel in $0.5 \mathrm{M} \mathrm{HCl}$ solution. Corros. Sci. 2019, 151, 132-142. [CrossRef]

12. Aslam, R.; Huda, M.M.; Obot, I.B.; Alamri, A.H. Ionic liquids derived from $\alpha$-amino acid ester salts as potent green corrosion inhibitors for mild steel in $1 \mathrm{M} \mathrm{HCl}$. J. Mol. Liq. 2020, 318, 113982. [CrossRef]

13. Onyeachu, I.B.; Obot, I.B.; Sorour, A.A.; Abdul-Rashid, M.I. Green corrosion inhibitor for oilfield application I: Electrochemical assessment of 2-(2-pyridyl) benzimidazole for API X60 steel under sweet environment in NACE brine ID196. Corros. Sci. 2019, 150, 183-193. [CrossRef]

14. Izadi, M.; Shahrabi, T.; Ramezanzadeh, B. Active corrosion protection performance of an epoxy coating applied on the mild steel modified with an eco-friendly sol-gel film impregnated with green corrosion inhibitor loaded nanocontainers. Appl. Surf. Sci. 2018, 440, 491-505. [CrossRef]

15. Machado-Fernandes, C.; Alvarez, L.X.; Santos, N.E.; Maldonado-Barrios, A.C.; Ponzio, E.A. Green synthesis of 1-benzyl-4phenyl-1H-1,2,3-triazole, its application as corrosion inhibitor for mild steel in acidic medium and new approach of classical electrochemical analyses. Corros. Sci. 2019, 149, 185-194. [CrossRef]

16. Mobin, M.; Basik, M.; Shoeb, M. A novel organic-inorganic hybrid complex based on Cissus quadrangularis plant extract and zirconium acetate as a green inhibitor for mild steel in $1 \mathrm{M} \mathrm{HCl}$ solution. Appl. Surf. Sci. 2019, 469, 387-403. [CrossRef]

17. Sun, X.; Yu, L. Investigation of polyacrylamide containing capsaicin monomer as a novel corrosion inhibitor for mild steel in hydrochloric acid. Mater. Corros. 2018, 69, 1095-1103. [CrossRef]

18. Zafari, S.; Sarabi, A.A.; Movassagh, B. A novel green corrosion inhibitor based on task-specific benzimidazolium ionic liquid for carbon steel in HCl. Corros. Eng. Sci. Technol. 2020, 55, 589-601. [CrossRef]

19. Sanatgar, S.M.; Peyvandi, K. New edible additives as green inhibitors for preventing methane hydrate formation. J. Environ. Chem. Eng. 2019, 7, 103172. [CrossRef]

20. Yang, H.M. Role of Organic and Eco-Friendly Inhibitors on the Corrosion Mitigation of Steel in Acidic Environments-A State-of-Art Review. Molecules 2021, 26, 3473. [CrossRef] [PubMed]

21. Verma, C.; Ebenso, E.E.; Bahadur, I.; Quraishi, M.A. An overview on plant extracts as environmental sustainable and green corrosion inhibitors for metals and alloys in aggressive corrosive media. J. Mol. Liq. 2018, 266, 577-590. [CrossRef]

22. Guedes, L.A.L.; Bacca, K.G.; Lopes, N.F.; Da Costa, E.M. Tannin of Acacia mearnsii as green corrosion inhibitor for AA7075-T6 alluminum alloy in acidic medium. Mater. Corros. 2019, 70, 1288-1297. [CrossRef]

23. Pérez-Miranda, S.; Zamudio-Rivera, L.S.; Cisneros-Dévora, R.; George-Téllez, R.; Fernández, F.J. Theoretical insight and experimental elucidation of desferrioxamine B from Bacillus sp. AS7 as a green corrosion inhibitor. Corros. Eng. Sci. Technol. 2020, 56, 93-101. [CrossRef]

24. Saxena, A.; Prasad, D.; Haldhar, R.; Singh, G.; Kumar, A. Use of Sida cordifolia extract as green corrosion inhibitor for mild steel in $0.5 \mathrm{M} \mathrm{H}_{2} \mathrm{SO}_{4}$. J. Environ. Chem. Eng. 2018, 6, 694-700. [CrossRef]

25. Haris, N.I.N.; Sobri, S.; Yusof, Y.A.; Kassim, N. Oil palm empty fruit bunch extract and powder as an eco-friendly corrosion inhibitor for mild steel: A comparison study. Mater. Corros. 2019, 70, 2326-2333. [CrossRef] 
26. Anupama, K.K.; Ramya, K.; Shainy, K.M.; Joseph, A. Adsorption and electrochemical studies of Pimenta dioica leaf extracts as corrosion inhibitor for mild steel in hydrochloric acid. Mater. Chem. Phys. 2015, 167, 28-41. [CrossRef]

27. Hussin, M.H.; Rahim, A.A.; Ibrahim, M.N.M.; Brosse, N. Improved corrosion inhibition of mild steel by chemically modified lignin polymers from Elaeis guineensis agricultural waste. Mater. Chem. Phys. 2015, 163, 201-212. [CrossRef]

28. Zhang, B.; He, C.; Wang, C.; Sun, P.; Li, F.; Lin, Y. Synergistic corrosion inhibition of environment-friendly inhibitors on the corrosion of carbon steel in soft water. Corros. Sci. 2015, 94, 6-20. [CrossRef]

29. Ji, G.; Anjum, S.; Sundaram, S.; Prakash, R. Musa paradisica peel extract as green corrosion inhibitor for mild Steel in $\mathrm{HCl}$ solution. Corros. Sci. 2015, 90, 107-117. [CrossRef]

30. Ngobiri, N.C.; Oguzie, E.E.; Li, Y.; Liu, L.; Oforka, N.C.; Akaranta, O. Eco-Friendly Corrosion Inhibition of Pipeline Steel Using Brassica oleracea. Int. J. Corros. 2015, 2015, 404139. [CrossRef]

31. El Hamdani, N.; Fdil, R.; Tourabi, M.; Jama, C.; Bentiss, F. Alkaloids extract of Retama monosperma (L.) Boiss. seeds used as novel eco-friendly inhibitor for carbon steel corrosion in $1 \mathrm{M} \mathrm{HCl}$ solution: Electrochemical and surface studies. Appl. Surf. Sci. 2015, 357, 1294-1305. [CrossRef]

32. Rajeswari, V.; Kesavan, D.; Gopiraman, M.; Viswanathamurthi, P.; Poonkuzhali, K.; Palvannan, T. Corrosion inhibition of Eleusine aegyptiaca and Croton rottleri leaf extracts on cast iron surface in $1 \mathrm{M} \mathrm{HCl} \mathrm{medium.} \mathrm{Appl.} \mathrm{Surf.} \mathrm{Sci.} \mathrm{2014,} \mathrm{314,} \mathrm{537-545.} \mathrm{[CrossRef]}$

33. Heuer, B.; Yaniv, Z.; Ravina, I. Effect of late salinization of chia (Salvia hispanica), stock (Matthiola tricuspidata) and evening primrose (Oenothera biennis) on their oil content and quality. Ind. Crops Prod. 2002, 15, 163-167. [CrossRef]

34. Peiretti, P.G.; Gai, F. Fatty acid and nutritive quality of chia Salvia hispanica L. seeds and plant during growth. Anim. Feed Sci. Technol. 2009, 148, 267-275. [CrossRef]

35. Chicco, A.G.; D’Alessandro, M.E.; Hein, G.J.; Oliva, E.M.; Lombardo, Y.B. Dietary chia seed (Salvia hispanica L.) rich in $\alpha$-linolenic acid improves adiposity and normalises hypertriacylglycerolaemia and insulin resistance in dyslipaemic rats. Br. J. Nutr. 2009, 101, 41-50. [CrossRef] [PubMed]

36. Vázquez-Ovando, A.; Rosado-Rubio, G.; Chel-Guerrero, L.; Betancur-Ancona, D. Physicochemical properties of a fibrous fraction from chia (Salvia hispanica L.). Food Sci. Technol. 2009, 42, 168-173.

37. Hermoso-Diaz, I.A.; Velázquez-Gonzalez, M.A.; Lucio-Garcia, M.A.; Gonzalez-Rodriguez, J.G. A Study of Salvia hispanica as Green Corrosion Inhibitor for Carbon Steel in Sulfuric Acid. Chem. Sci. Rev. Lett. 2014, 3, 685-697.

38. Cao, Z.; Tang, Y.; Cang, H.; Xu, J.; Lu, G.; Jing, W. Novel benzimidazole derivatives as corrosion inhibitors of mild steel in the acidic media. Part II: Theoretical studies. Corros. Sci. 2014, 83, 292-298. [CrossRef]

39. Yadav, M.; Sharma, D.; Kumar, S.; Kumar, S.; Bahadur, I.; Ebenso, E.E. Electrochemical and Theoretical Studies on Amino Phosphonates as Efficient Corrosion Inhibitor for N80 Steel in Hydrochloric Acid Solution. Int. J. Electrochem. Sci. 2014, 9, 6580-6593.

40. Obot, I.B.; Macdonalda, D.D.; Gasem, Z.M. Density functional theory (DFT) as a powerful tool for designing new organic corrosion inhibitors. Part 1: An overview. Corros. Sci. 2015, 99, 1-30. [CrossRef]

41. Wazzan, N.A. DFT calculations of thiosemicarbazide, arylisothiocynates, and 1-aryl-2,5-dithiohydrazodicarbonamides as corrosion inhibitors of copper in an aqueous chloride solution. J. Ind. Eng. Chem. 2015, 26, 291-308. [CrossRef]

42. Arslan, T.; Kandemirli, F.; Ebenso, E.E.; Love, I.; Alemu, H. Quantum chemical studies on the corrosion inhibition of some sulphonamides on mild steel in acidic medium. Corros. Sci. 2009, 51, 35-47. [CrossRef]

43. Gece, G. T The use of quantum chemical methods in corrosion inhibition studies. Corros. Sci. 2008, 50, 2981-2992. [CrossRef]

44. Amovilli, C.; Barone, V.; Cammi, R.; Cancés, E.; Cossi, M.; Mennucci, B.; Pomelli, C.S.; Tomasi, J. Recent advances in the description of solvent effects with the polarizable continuum model. Adv. Quantum Chem. 1998, 32, $27-261$.

45. Tomasi, J.; Mennucci, B.; Cammi, R. Quantum mechanical continuum solvation models. Chem. Rev. 2005, 105, 2999-3093. [CrossRef]

46. Obot, I.B.; Gasem, Z.M. Theoretical evaluation of corrosion inhibition performance of some pyrazine derivatives. Corros. Sci. 2014, 83, 359-366. [CrossRef]

47. Parr, R.G. Density functional theory of atoms and molecules. Horiz. Quantum Chem. 1980, 3, 5-15. [CrossRef]

48. Chattaraj, P.K.; Maiti, B.; Sarkar, U. Philicity: A unified treatment of chemical reactivity and selectivity. J. Phys. Chem. 2003, 107, 4973-4975. [CrossRef]

49. Morell, C.; Grand, A.; Toro-Labbe, A. Theoretical support for using the Delta f(r) descriptor. Chem. Phys. Lett. 2006, 425, 342-346. [CrossRef]

50. Hsissou, R. Review on epoxy polymers and its composites as a potential anticorrosive coatings for carbon steel in $3.5 \% \mathrm{NaCl}$ solution: Computational approaches. J. Mol. Liq. 2021, 336, 116307. [CrossRef]

51. Verna, C.; Olasunkanmi, L.O.; Ebenso, E.E.; Quraishi, M.A. Adsorption characteristics of Green 5-arylaminomethylene pyrimidine2,4,6-triones on mild Steel Surface in acidic medium: Experimental and computational approach. Res. Phys. 2018, 8, 657-670.

52. Free, M.L. Understanding the effect of surfactant aggregation on corrosion inhibition of mild steel in acid medium. Corros. Sci. 2002, 44, 2865-2870. [CrossRef]

53. Tao, Z.; Zhang, S.; Li, W.; Hou, B. Corrosion inhibition of mild steel in acidic solution by some oxo-triazole derivatives. Corros. Sci. 2009, 51, 2588-2595. [CrossRef]

54. Gusmano, G.; Labella, P.; Montesperelli, G.; Privitera, A.; Tassinari, S. Study of the Inhibition Mechanism of Imidazolines by Electrochemical Impedance Spectroscopy. Corrosion 2006, 62, 576-583. [CrossRef] 
55. Zhang, G.; Chen, C.; Lu, M.; Chai, C.; Wu, Y. Evaluation of inhibition efficiency of an imidazoline derivative in $\mathrm{CO}_{2}$-containing aqueous solution. Mater. Chem. Phys. 2007, 105, 331-340. [CrossRef]

56. Amin, M.A.; Abd El-Rehim, S.S.; El-Sherbini, E.E.F. The inhibition of low carbon steel corrosion in hydrochloric acid solutions by succinic acid, Part I weight loss, polarization, EIS, PZC, EDX and SEM studies. Electrochim. Acta 2007, 52, 3588-3600. [CrossRef]

57. Bontiss, F.; Lagrence, M.; Traisnel, M. 2,5-Bis(n-Pyridyl)-1,3,4-Oxadiazoles as Corrosion Inhibitors for Mild Steel in Acidic Media. Corrosion 2000, 56, 733-742. [CrossRef]

58. Jiang, X.; Zheng, Y.G.; Ke, W. Effect of flow velocity and entrained sand on inhibition performances of two inhibitors for $\mathrm{CO}_{2}$ corrosion of $\mathrm{N} 80$ steel in 3\% NaCl solution. Corros. Sci. 2005, 47, 2636-2658. [CrossRef]

59. Oguzie, E.E.; Li, Y.; Wang, F.H. Corrosion inhibition and adsorption behavior of methionine on mild steel in sulfuric acid and synergistic effect of iodide ion. J. Colloid Interf. Sci. 2007, 310, 90-98. [CrossRef] [PubMed]

60. Musa, A.Y.; Kadhum, A.A.H.; Mohamad, A.B.; Rahoma, A.A.B.; Mesmari, H. Electrochemical and quantum chemical calculations on 4,4-dimethyloxazolidine-2-thione as inhibitor for mild steel corrosion in hydrochloric acid. J. Mol. Struct. (Theochem) 2010, 969, 233-243. [CrossRef]

61. Obi-Egbedi, N.O.; Essien, K.E.; Obot, I.B.; Ebenso, E.E. Computational Simulation and Statistical Analysis on the Relationship between Corrosion Inhibition Efficiency and Molecular Structure of Some Phenanthroline Derivatives on Mild Steel Surface. Int. J. Electrochem. Sci. 2011, 6, 5649-5675.

62. Obot, I.B.; Obi-Egbedi, N.O. Ginseng Root: A new Efficient and Effective Eco-Friendly Corrosion Inhibitor for Aluminium Alloy of type AA 1060 in Hydrochloric Acid Solution. Int. J. Electrochem. Sci. 2009, 4, 1277-1288.

63. Guo, L.; Safi, Z.S.; Kaya, S.; Shi, W.; Tüzün, B.; Altunay, N.; Kaya, C. Anticorrosive effects of some thiophene derivatives against the corrosion of iron: A computational study. Front. Chem. 2018, 6, 155. [CrossRef] [PubMed]

64. Al-Amiery, A.A.; Kadhum, A.A.H.; Kadihum, A.; Mohamad, A.B.; How, C.K.; Junaedi, S. Inhibition of Mild Steel Corrosion in Sulfuric Acid Solution by New Schiff Base. Materials 2014, 7, 787-804. [CrossRef] [PubMed] 